
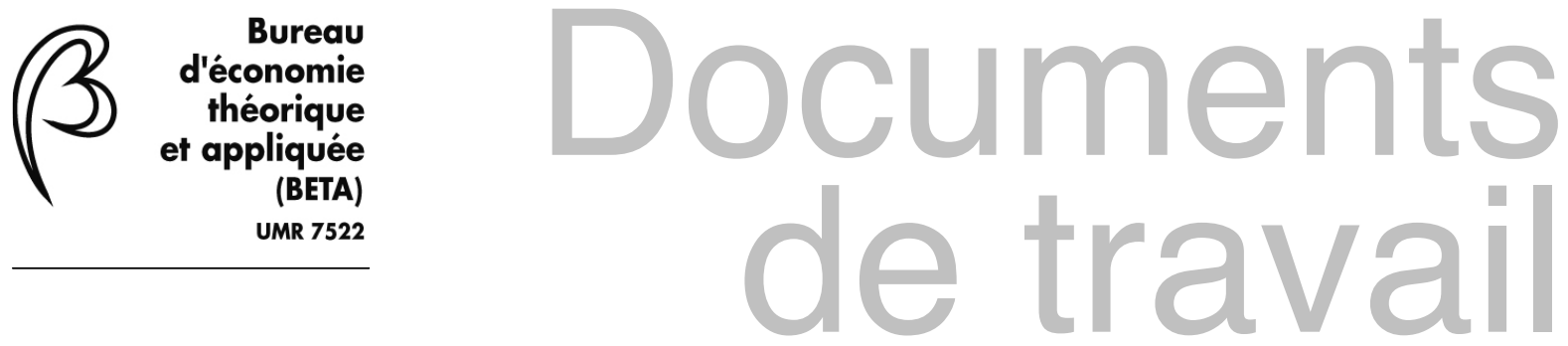

« Nudge and Tax in an Environmental Public Goods Experiment: Does Environmental Sensitivity Matter?»

\author{
$\underline{\text { Auteurs }}$ \\ Kene Boun My, Benjamin Ouvrard \\ Document de Travail $n^{\circ} 2017-06$
}

Février 2017

\begin{abstract}
Faculté des sciences économiques et de gestion
\end{abstract}

61 avenue de la Forêt Noire F-67085 Strasbourg Cedex

Secrétariat du BETA Géraldine Del Fabbro Tél. : (33) 0368852069 Fax : (33) 0368852070 g.delfabbro@unistra.fr www.beta-umr7522.fr 


\title{
Nudge and Tax in an Environmental Public Goods Experiment: Does Environmental Sensitivity Matter?*
}

\author{
Kene Boun $\mathrm{My}^{\dagger} \quad$ Benjamin Ouvrard ${ }^{\ddagger}$
}

February 15, 2017

\begin{abstract}
We provide an experimental test of the theoretical predictions obtained in $\mathrm{Ou}-$ vrard and Spaeter (2016). A public goods experiment is proposed in which the subjects can contribute to reduce the level of pollution, which is stochastic. A nudge (announcement of the socially optimal contribution) and a tax are implemented to improve the level of contributions. The environmental sensitivity and optimism of the subjects are also elicited. Our first result shows that the implementation of the nudge does not perform as well as the implementation of the tax. The reaction to the nudge depends directly on individuals' environmental sensitivity, contrary to the reaction to the tax. Secondly, the nudge performs well with highly sensitive subjects only during the first half of its implementation. Lastly, the efficiency analysis shows that the implementation of the nudge significantly decreases the groups' welfare for the least sensitive subjects, in comparison to the baseline. In sum, these results tend to corroborate the predictions obtained in Ouvrard and Spaeter (2016).
\end{abstract}

Key Words : incentives; nudge; environmental sensitivity; optimism; tax.

JEL Codes : C91, H41, Q58.

${ }^{*}$ We would like to thank particularly Giuseppe Attanasi, Gary Charness, Mathieu Lefebvre, Phu Nguyen-Van, Anne Rozan and Sandrine Spaeter for their helpful comments. We are also grateful to the participants at the Strasbourg Wokshop on Experimental Economics (Strasbourg, 2016) and at the international colloquium Conative Nudges: Changes in Desires (Rennes, 2016). This experiment received financial support from the GERIHCO project.

†BETA, CNRS, bounmy@unistra.fr

BETA, CNRS and University of Strasbourg, bouvrard@unistra.fr 


\section{Introduction}

A key question in economics is how to provide incentives to individuals to adopt a desired behavior. One solution is to implement monetary incentives. They are well-known to be efficient, in particular in environmental economics (see Cropper and Oates (1992) and Helfand et al. (2003)). However, monetary incentives are also well known to crowd out individuals' motivation to contribute voluntarily (Frey (1992), Gneezy and Rustichini (2000), Bénabou and Tirole (2003, 2006)).

An alternative to these monetary incentives are nudges (Thaler and Sunstein (2009)). They are simple, costless and non-coercive actions designed to correct individuals' behavior. ${ }^{1}$ To study their effects, different natural field experiments on energy conservation have been conducted in psychology (Schultz et al. (2007), Goldstein et al. (2008), Nolan et al. (2008)) and in economics (Allcott (2011), Ayres et al. (2013), Costa and Kahn (2013), Ferraro and Price (2013), Egebark and Ekström (2016)). They all exhibit interesting results in terms of energy reduction. Recently, some laboratory experiments have been conducted to study the impact of nudges (Delaney and Jacobson (2016), Lefebvre and Stenger (2016)). Laboratory experiments present the advantage of having a greater control on the environment compared to natural field experiments. These lab experiments also exhibit encouraging results both in terms of efficiency (Delaney and Jacobson (2016)) and in terms of persistance of the effects of nudges (Lefebvre and Stenger (2016)). Finally, Momsen and Stoerk (2014) compare different nudges through an online experiment. Only the implementation of the default option was found to be efficient.

Up to now, few authors have proposed a way to model the reaction to a nudge (Harding and Hsiaw (2014), Farhi and Gabaix (2015), Ouvrard and Spaeter (2016)). Notwithstanding, models are necessary to obtain theoretical predictions to provide guidelines for policymakers. But such models should be validated with empirical evidence.

To fill this gap, in this paper we propose an experimental test of the predictions of the model proposed by Ouvrard and Spaeter (2016), who focus on the implementation of a "green nudge". More precisely, the authors propose a model in which individuals can contribute to improve environmental quality. Pollution is stochastic and individuals differ

\footnotetext{
${ }^{1}$ Sunstein (2014) provides examples of nudges: default option, simplification, use of social norms, warnings, disclosure policies, etc.
} 
in their risk perception: they are more or less optimistic concerning the risk of pollution. Moreover, individuals are also heterogeneous in their environmental sensitivity. ${ }^{2}$ Ouvrard and Spaeter (2016) propose a way to model individuals' reactions to a nudge, which is the announcement of the socially optimal level of contribution. They made the hypothesis that the marginal reaction to the nudge depends on environmental sensitivity.

In addition to be costless incentives, the authors also highlight that nudges require less information than a tax to be implemented. Indeed, the tax they study is a tax on the difference between an individual's contribution and the socially optimal one. They argue that the implementation of their nudge does not require the regulator to have knowledge about individual contributions, as the agents should react by themselves when receiving the nudge (as long as they contribute less than the announced value). Their nudge acts in a way which is similar to an anchor (Tversky and Kahneman (1974)).

To test most of their predictions, we propose an environmental public goods game in which subjects can contribute to reduce the level of pollution. We first determine the subjects' environmental sensitivity to form groups of subjects with the same sensitivity (high and low). This allows for a direct inter-group comparison. We compare the implementation of a nudge with that a tax. We obtain three main results. Firstly, as hypothesized in Ouvrard and Spaeter (2016), the reaction to a nudge depends directly on environmental sensitivity, contrary to a tax. Secondly, while subjects increased their level of contribution during the whole implementation of the tax, we found that the nudge induced such an increase during the first half of its implementation (only for subjects with a high environmental sensitivity). Thirdly, conducting a welfare analysis, we show that the implementation of the nudge significantly decreases the welfare of groups of subjects with low environmental sensitivity.

The rest of the paper is organized as follows. The related literature is presented in Section 2. Then we propose a simpler version of Ouvrard and Spaeter (2016)'s model in Section 3. The experimental design is presented in Section 4. The results of the experiment are described in Section 5. We conduct a welfare anlysis in Section 6 and a discussion with a conclusion is presented in Section 7 .

\footnotetext{
${ }^{2}$ In their model, environmental sensitivity can be understood as a health characteristic, or as individuals' beliefs regarding the environment.
} 


\section{Related literature}

Our study may be related to other experiments. We distinguish among three different groups which we describe below.

First, our experiment is related to experiments dealing with the study of the effects of monetary and non-monetary incentives. In particular, several authors have studied mechanisms based on social approval by peers (Masclet et al. (2003), Rege and Telle (2004), Dugar (2010, 2013), Lefebvre and Stenger (2016)), inducing higher level of contributions during their implementation. ${ }^{3}$ In another experiment, Delaney and Jacobson (2016) consider the implementation of normative messages to reduce the extraction of resources in a common pool resource game. In a first treatment an informative message was implemented (it informed subjects who over-extracted, to reduce their investment to increase their payoff). When this message was implemented, a decrease of $0.549 \%$ of the level of extraction was observed. The highest decrease in the level of extraction, of $11.441 \%$, was observed when the normative message was implemented (informing over-extracting subjects that subjects in other groups extracted less and earned more as a consequence).

Considering the nature of our nudge, our study can be related to a second group of experiments dealing with recommended play (or suggested play). ${ }^{4}$ Marks et al. (1999) consider the implementation of suggested play in a threshold public goods game. The authors show that this mechanism helps to significantly increase the level of contributions only when subjects have heterogeneous valuations of the public good. ${ }^{5}$ This result is reinforced by those obtained by Croson and Marks (2001). In a similar experiment, the authors show that this mechanism is not efficient when subjects are homogeneous in their valuation of the public good. Oxoby and Spraggon (2007) use this mechanism as a complement to monetary incentives to reduce the level of ambient pollution. The authors do not find a significant effect of this mechanism. Finally, Dal Bó and Dal Bó (2014) compare the implementation of moral appeals with suggested play. They obtain that moral appeals lead to a higher level of contributions than under the implementation of suggested play.

\footnotetext{
${ }^{3}$ Chaudhuri (2011) proposes a review of monetary and non-monetary incentives to maintain cooperation over time in public good games.

${ }^{4}$ Indeed, our nudge is based on the disclosure of the socially optimal level of contribution.

${ }^{5}$ In the heterogeneous preferences game, the payoffs from the public good provision differ between subjects.
} 
Lastly, through the environmental context we give to this experiment, and the risk associated with the pollution that subjects face, it is also related to experiments on climate change mitigation. Milinski et al. (2008) propose an experiment in which subjects could invest a part of their initial endowment in a "climate account". In the last period, if the group does not reach a threshold of 120 euros invested in the climate account, then they can lose their remaning endownent with given probability (differing across the treatments). The authors show that the higher the probability of loss is, the higher is the probability to achieve the threshold of 120 euros at the group level. Using the same experiment, Tavoni et al. (2011) study inequity between subjects (some subjects in the group could not choose the amount invested in the climate account during the three first periods). They find that the probability of attaining the threshold is higher when there is inequity between subjects than where there is equity. In a similar experiment, Dannenberg et al. (2015) compare situations under certainty, risk and ambiguity. They show that the probability to achieve the threshold is higher under certainty and then under risk. Finally, Hasson et al. (2010, 2012) propose to study the tradeoff between climate change mitigation and adaptation. Hasson et al. (2010) compare a treatment in which the cost induced by the disaster is low, with a treatment in which this cost is high. In the first treatment, $47 \%$ of the subjects chose to mitigate climate change, while $25 \%$ of the subjects in the second treatment chose to mitigate climate change. Hasson et al. (2012) compare the same game under risk and certainty, but do not find significant differences in the choices made by subjects in these two situations.

\section{Theoretical background}

In this section, we propose a model of voluntary contributions to improve environmental quality, on which the design of the experiment is built. This is a simpler version of the model developed in Ouvrard and Spaeter (2016). We start by presenting the benchmark model in which no incentives are implemented. We then introduce a tax on the difference between the socially optimal contribution and the level of contribution of the individuals under study. Finally, we present the modeling of the reaction to a nudge that takes the form of the announcement of the socially optimal contribution. 


\subsection{Benchmark model without outside incentives}

In this subsection, we start by presenting the individuals' private optima. We then compare with the regulator's program.

\subsubsection{The individuals' program}

Consider an economy with $N$ individuals facing a stochastic level of pollution. The level of pollution for the current period is given by:

$$
\tilde{P}=\tilde{E}-b(A)
$$

with $\tilde{E}$ being the amount of pollution emitted by the current production. More precisely, $\tilde{E}$ is a random variable which can take two values, $\underline{E}$ or $\bar{E}$. Assume that the experts of the regulator have determined that the proportion of pollution coming from production will be low $(\underline{E})$, with probability $q$, and high $(\bar{E})$ with probability $(1-q)$. This level of pollution can be reduced by individuals' voluntary contributions $a_{i}$, with $A=\sum_{i=1}^{n} a_{i}$. Thus, function $b(A)$ is the social benefit from pollution reduction, with $b^{\prime}(A)>0$ and $b^{\prime \prime}(A)<0$.

Pollution affects individuals through the convex disutility function $d\left(\tilde{P}, s^{j}\right)$, with $d_{P}>$ $0, d_{P P} \geq 0$ and $d_{P}<\infty . s^{j}$ is a qualitative variable defining individual $i$ 's sensitivity to the environment ${ }^{6}$. It can be low, $s^{l}$, or high, $s^{h}$, with $s^{h}>s^{l}$. Finally, let us assume that $d_{P s^{j}}>0$ : two individuals differing in their individual sensitivity to the environment do not incur the same disutility regarding pollution (for a same level of pollution). The more sensitive the individuals, the higher their marginal disutility regarding pollution.

In addition to this heterogeneity in environmental sensitivity, individuals may be more or less confident at the announcement of the distribution of the risk of pollution from the regulator. Precisely, individuals differ in their risk perception and they may disagree with the probabilities announced by the regulator's experts. Similarly to Salanié and Treich (2009), we characterize two types of individuals. One type not very optimistic who considers that the proportion of pollution coming from production will be low $(\underline{E})$

\footnotetext{
${ }^{6}$ Environmental sensitivity may be understood as a health characteristic (individuals may not live in highly polluted environment because it is not good for their health), or can also represent personnal convictions (individuals are highly sensitive $\left(s^{h}\right)$ to the environment because they have been educated in a way such that they consider the impact of their actions on the environment).
} 
with probability $r$, and high $(\bar{E})$ with probability $(1-r)$, with $r>q$. The other type highly optimistic, considering that the proportion of pollution coming from production will be low $(\underline{E})$ with probability $v$, and high $(\bar{E})$ with probability $(1-v)$, with $v>r>q$. Formally, let us denote as $\pi_{i}$ (respectively $1-\pi_{i}$ ) individual $i$ 's beliefs on the risk of a low (high) pollution: $\pi_{i}=\{r, v\}$. In the following, let us denote as $\left(\pi_{i}, s^{j}\right)$ an individual with beliefs $\left(\pi_{i}, 1-\pi_{i}\right)$ and sensitivity $s^{j 7}$.

Finally, individuals are endowed with the fixed wage $w$, that can be shared between private consumption $c_{i}$ and contributions $a_{i, j}$ to improve environmental quality. The utility of consumption is $u\left(c_{i}\right)$, with $u^{\prime}()>$.0 and $u^{\prime \prime}() \leq$.0 . Individual $i$ 's expected utility can thus be written as:

$$
\max _{a_{i, j}} \mathbb{E}\left(U_{i, j}\right)=u\left(w-a_{i, j}\right)-\pi_{i} d\left(\underline{P}, s^{j}\right)-\left(1-\pi_{i}\right) d\left(\bar{P}, s^{j}\right)
$$

Each individual maximizes (2) subject to $a_{i, j} \geq 0$. The first order condition for an interior solution is:

$$
-u^{\prime}\left(w-a_{i, j}^{p}\right)+b^{\prime}(A)\left(\pi_{i} d_{P}\left(\underline{P}, s^{j}\right)+\left(1-\pi_{i}\right) d_{P}\left(\bar{P}, s^{j}\right)\right)=0
$$

where $a_{i, j}^{p}$ is individual $i$ 's private level of contribution. The second order condition is satisfied $^{8}$.

\subsubsection{The regulator's program}

We now present the regulator's program. Let us assume that the regulator has some information on the individuals' sensitivity to the environment (he knows the proportion of highly sensitive individuals for instance), but has no information on the individuals' confidence about the risk of pollution. ${ }^{9}$ Thus, let us consider a paternalistic regulator who takes into account his own beliefs $q$ and $(1-q)$. His program writes:

$$
\max _{a_{i, j}} \sum_{i}^{N}\left(u\left(w-a_{i, j}\right)-q d\left(\underline{P}, s^{j}\right)-(1-q) d\left(\bar{P}, s^{j}\right)\right)
$$

\footnotetext{
${ }^{7}$ Four different profiles are possible: $(r, l),(r, h),(v, l)$ and $(v, h)$. Notice that we could also have the case of individuals sharing the same beliefs as the regulator: $(q, l)$ and $(q, h)$, with $\pi_{r}=q$.

${ }^{8}$ We have:

$u^{\prime \prime}\left(w-a_{i, j}^{p}\right)+b^{\prime \prime}(A)\left(\pi_{i} d_{P}\left(\underline{P}, s^{j}\right)+\left(1-\pi_{i}\right) d_{P}\left(\bar{P}, s^{j}\right)\right)-\left(b^{\prime}(A)\right)^{2}\left(\pi_{i} d_{P P}\left(\underline{P}, s^{j}\right)+\left(1-\pi_{i}\right) d_{P P}\left(\bar{P}, s^{j}\right)\right)<0$

${ }^{9}$ The proportion of individuals having voted for green parties may serve as a proxy.
} 
Proposition 1 Consider a population whose individuals differ in their environmental sensitivity and in their risk perception. Then, if the regulator is paternalistic,

i) All individuals undercontribute compared to the social optimum.

ii) The most optimistic individuals are not necessary the lowest contributors. In particular, we may have: $a_{v, l}^{p}<a_{r, l}^{p}<a_{r, h}^{p}$ and $a_{v, l}^{p}<a_{v, h}^{p}<a_{r, h}^{p}$, but we cannot say anything else without additional assumptions.

Ouvrard and Spaeter (2016) obtain similar results. Point i) is due to the fact that individuals do not consider the impact of their contributions on the benefits for others and is a classical result in public economics. Point ii) is less obvious and is due to the introduction of individuals' sensitivity $s^{j}$. This result differs from Etner et al. (2007, 2009). In their paper, individuals' differences in contributions were only explained by a difference in risk perception. In our case, a difference in environmental sensitivity between two individuals can more than compensate a difference in risk perception.

Given that individuals undercontribute compared to the social optimum (computed with the regulator's beliefs), we first consider the implementation of a tax, and then of a nudge.

\subsection{Model with a tax}

Let us now consider the introduction of an exogenous tax to increase individuals' contributions to improve environmental quality. More precisely, individuals are taxed on the difference between the social optimum (computed with the regulator's beliefs) and their contributions. We consider a linear tax, $t\left(a_{i, j}\right)$, with $t^{\prime}\left(a_{i, j}\right)<0$ and

$$
t\left(a_{i, j}\right)= \begin{cases}\tau\left(a^{*}-a_{i, j}\right) & \text { if } a_{i, j}<a^{*} \\ 0 & \text { if } a_{i, j} \geq a^{*}\end{cases}
$$

Individuals solve the following program:

$$
\max _{a_{i, j}} \quad u\left(w-a_{i, j}-t\left(a_{i, j}\right)\right)-\pi_{i} d\left(\underline{P}, s^{j}\right)-\left(1-\pi_{i}\right) d\left(\bar{P}, s^{j}\right)
$$

The first order condition for an interior solution $\left.a_{i}^{t}\right)$ is:

$$
-(1-\tau) u^{\prime}\left(w-a_{i, j}^{t}-t\left(a_{i, j}^{t}\right)\right)+b^{\prime}(A)\left(\pi_{i} d_{P}\left(\underline{P}, s^{j}\right)+\left(1-\pi_{i}\right) d_{P}\left(\bar{P}, s^{j}\right)\right)=0
$$

We obtain the following proposition, 
Proposition 2 Let us consider a regulator who implements an exogenous tax on the contributions that are not provided compared to the social optimum. Then, for individuals $(r, l)$ and $(v, h)$ we have:

i) If $a_{r, l}^{p}=a_{v, h}^{p}$ then $a_{r, l}^{t} \gtrless a_{v, h}^{t}$ iff $d_{P P P} \lessgtr 0$.

ii) If $a_{r, l}^{p}>a_{v, h}^{p}$ then $a_{r, l}^{t}>a_{v, h}^{t}$ iff $d_{P P P} \leq 0$. We cannot conclude otherwise.

iii) If $a_{r, l}^{p}<a_{v, h}^{p}$ then $a_{r, l}^{t}>a_{v, h}^{t}$ iff $d_{P P P} \geq 0$. We cannot conclude otherwise.

According to points i) and ii), if agents are non-prudent, then the implementation of an exogenous tax does not necessarily take into account individuals' environmental sensitivity: a few optimistic and sensitive agent contributing the same (or more) than a highly optimistic and sensitive agent in the absence of outside incentive, may contribute more than this last agent under tax implementation if both agents are non-prudent. Ouvrard and Spaeter (2016) argue that the hypothesis of non-prudent individuals is the most likely hypothesis. Indeed, following Menezes et al. (1980), Kimball (1990) or Crainich et Eeckhoudt (2008), this means that individuals prefer combining an additional risk of pollution with the low state of pollution $(\underline{E})$. As a consequence, the tax does not necessarily allow discrimination of individuals' contributions according to their environmental sensitivity.

In the experiment described below, we will not test precisely this result as we do not determine individuals' prudence. However, we still consider the implementation of such a tax, to compare its efficiency with that of a nudge.

We detail our modelling of the reaction to a nudge in the next subsection.

\subsection{Implementation of a nudge}

As in Ouvrard and Spaeter (2016), the nudge we study is the dissemination of some information. More precisely, individuals are informed about the level of the socially optimal level of contribution. Let us assume that individuals' reaction to such a nudge is modelled by the function $g\left(a_{i, j}-\hat{a} \mid s^{j}\right)$, with $g(0)=0, g_{a_{i, j}}<0$ and $g_{a_{i, j} a_{i, j}} \geq 0$. The intuition is that individuals will incur a psychological cost when deviating from the announcement. The announcement is assumed to act as a reference point (anchor) to individuals (Tversky and Kahneman (1974)).

We assume that the higher the marginal moral cost is, the higher the individual $i$ 's sensitivity to the environment: $g_{a_{i, j} s^{j}}\left(. \mid s^{j}\right)<0$. In the experiment described below, we are particularly interested in testing this assumption. 
Once the regulator makes his announcement, each individual solves the following program

$$
\max _{a_{i, j}} u\left(w-a_{i, j}\right)-\pi_{i} d\left(\underline{P}, s^{j}\right)-\left(1-\pi_{i}\right) d\left(\bar{P}, s^{j}\right)-g\left(a_{i, j}-\hat{a} \mid s^{j}\right)
$$

The first order condition for a private interior solution $a_{i, j}^{n}$ is given by:

$$
-u^{\prime}\left(w-a_{i, j}^{n}\right)+b^{\prime}(A)\left(\pi_{i} d_{P}\left(\underline{P}, s^{j}\right)+\left(1-\pi_{i}\right) d_{P}\left(\bar{P}, s^{j}\right)\right)-g_{a_{i}}\left(a_{i, j}^{n}-\hat{a} \mid s^{j}\right)=0
$$

Proposition 3 Consider a regulator who discloses information on the social optimum. Then:

i) All individuals increase their level of contributions.

ii) The most sensitive individuals react the most to a nudge. More precisely, if for two individuals $a_{r, l}^{p}=a_{v, h}^{p}$ and $a_{r, l}^{t}=a_{v, h}^{t}$, then $a_{r, l}^{n}<a_{v, h}^{n}$.

As in Ouvrard and Spaeter (2016), we obtain that the reaction to a nudge depends directly on individual environmental sensitivity (contrary to a tax as presented above). Such an instrument presents an advantage over the tax: the regulator does not have to know individual contributions. Only those deviating from the level announced should react. Concerning the tax presented previously, it is necessary to know the individual contributions in order to compute the amount to be paid.

In the following section, we describe the experimental protocol that we consider in order to test the predictions we obtained in the present section.

\section{Experiment}

The objective of this experiment is to test the predictions of the previous section. We first detail the design of the experiment. Then the predictions of the parametric protocol of the model and the behavioral hypotheses are presented.

\subsection{General features}

The experiment was implemented during 6 sessions each involving 24 subjects (144 subjects in total), in April 2016 in the Laboratory of Experimental Economics of Strasbourg (LEES). Sessions were completed in one hour. ${ }^{10}$ The average earnings of subjects was

\footnotetext{
${ }^{10}$ The program of this experiment was designed by Kene Boun My with the web platform EconPlay (www.econplay.fr).
} 
16.05 euros $(\mathrm{SD}=3.58)$.

\subsubsection{First task: General Ecological Behavior Scale}

First, the subjects were randomly assigned to a computer, and the instructions were read aloud. The subjects were informed that they would be participating in an economic experiment in which they would have to make investment decisions. They were told that the experiment involved 2 stages and that their total earnings would be the sum of their individual earnings in each stage. If the subjects had any questions, an experimenter came to answer them privately.

During the first stage, the subjects had to complete a questionnaire to determine their environmental sensitivity. 28 items (detailed in the appendix) were selected from the General Ecological Behavior (GEB) scale (Kaiser (1998)). ${ }^{11} 17$ items were framed positively and the 11 remaining ones negatively. The subjects had to give their level of agreement to each items. There were 5 possible answers: "never", "seldom", "sometimes", "often" and "always". The answers were recoded from 1 for "never" to 5 for "always" (the opposite for unecological items). The mean total score of the first session served as the reference for the other sessions $(M=104)$. Subjects whose score was below the mean were considered as the least sensitive to environmental matters. They were Player $A$ in the other stage of the experiment. Subjects with a score above the mean were considered as the most sensitive to environmental matters. They were Player B in the other stage. The subjects were not aware that their answers would determine their role in the other stages before the test. They were asked to answer honestly and were paid 5 euros for this task.

\subsubsection{Second task: Environmental public good game}

For the second stage of the game, subjects were anonymously assigned to fixed groups of four. They were informed that they would be Player A or Player B according to the answers they had given in the previous stage and that their group could be composed of A Players and/or B Players. ${ }^{12}$ They were told that the earnings for each kind of players

\footnotetext{
${ }^{11}$ In the original version of the questionnaire, subjects had to answer 40 questions. To save time, and not to bore the subjects, we chose to implement the reduced version with 28 questions proposed by Davis et al. $(2009,2011)$. This shorter version presents an acceptable reliability: $\alpha=0.76$ in Davis et al. (2009) and $\alpha=0.75$ in Davis et al. (2011).

${ }^{12}$ During the game, subjects knew the composition of $A$ Players and/or B Players in their group.
} 
would not be the same. To allow for a direct comparison between subjects, we formed groups of $A$ Players only, as well as groups of $B$ Players only. During the 6 sessions, we had 5 mixed groups that are not considered in the rest of this analysis.

The subjects played a 15 periods public goods game. In particular, they were told that they lived in a community in which, according to the government experts, there was a risk of pollution. The pollution was expected to be low with probability 0.5 , and high with probability 0.5 . Subjects were endowed with a fixed amount of 10 tokens that could be shared between a private account and an environmental account. They were informed that the private account was used for private consumption. An investment of one token in this account would only benefit the subject. The environmental account was a collective account used to reduce the level of pollution. An investment of one token in this account would reduce the level of pollution for all members of the group. In addition to a baseline, two treatments were implemented. In the first treatment (Nudge), a nudge was implemented. As detailed in the model in the previous section, it consisted in the announcement of the optimal contribution at the beginning of each period. In particular, the subjects could read the following message on their screen:

"The best solution for the environment and your group is to invest 10 tokens in the environmental account"

We are aware that such a message could induce experimenter demand effects, as emphasized by Zizzo (2010). However, we could argue that this is inherent to the use of nudges. Indeed, considering the field experiments that have been conducted so far (Schultz et al. (2007), Nolan et al. (2008), Goldstein et al. (2008), Allcott (2011), Ayres et al. (2013), Costa et Kahn (2013) or Ferraro and Price (2013)), households could deduce from reports sent to them (showing the mean energy consumption by silimar households) that they were being advised to reduce their energy consumption.

We nevertheless tried to limit them. In the instructions we emphasized that a message would appear on the screen and that the subjects would be completely free to follow the message or not. We reminded them that their decisions would be anonymous. Lastly, to limit social experimenter demand effects, the experimenter who conducted each session was not a professor in the University.

In the second treatment (Tax), the subjects were taxed on the difference between the 
socially optimal contribution and their actual level of contribution. The tax function is discussed in the next subsection.

Before the begining of the public goods game, the subjects had to complete a questionnaire to test their understanding of the game.

\subsubsection{Revised Life Orientation Test (LOT-R) and socio-economic questions}

At the end of the public goods game, the subjects' optimism was elicited using the Revised Life Orientation Test (LOT-R), proposed by Scheier et al. (1994) ${ }^{13}$ As for the GEB, the subjects had to give their level of agreement to 10 items, with 2 reversed ones. There were 5 possible answers: "Strongly disagree", "Disagree", "Neutral", "Agree" and "Strongly agree". The answers were recoded from 1 for "Strongly disagree" to 5 for "Strongly agree" (the opposite for reversed items). The total score could be between 10 and 50 . The subjects whose score was between 10 and 30 were considered as the least optimistic ones (those with with beliefs $\pi_{i}=r$ in the model presented in the previous section). Those whose score was between 31 and 50 were considered as the most optimistic subjects (those with with beliefs $\pi_{i}=v$ ). Socio-economic questions completed this questionnaire.

\subsection{Parametric protocol}

In the baseline and in the nudge treatment, subjects' earnings were given by the following payoff function:

$\pi_{i}=650+6\left(10-a_{i}\right)-0.175\left(10-a_{i}\right)^{2}-\left(\left(\tilde{E}-0.1 \sum_{i=1}^{4} a_{i}\right)^{2}-12.9 s^{j}\left(\tilde{E}-0.1 \sum_{i=1}^{4} a_{i}\right)\right)$

where $a_{i}$ is individual $i$ 's contribution, $s^{j} \in\left\{s^{l}, s^{h}\right\}$ his/her environmental sensitivity with $s^{l}=0$ and $s^{h}=1$. $\quad \tilde{E}$ is the current level of pollution, which is equal to 5 in the case of a low level of pollution and to 20 in the case of a high level of pollution. ${ }^{14}$ This function satisfies the properties of the model discussed in the previous section. In particular, $650+6\left(10-a_{i}\right)-0.175\left(10-a_{i}\right)^{2}$ corresponds to the utility of consumption, and $\left(\left(\tilde{E}-0.1 \sum_{i=1}^{4} a_{i}\right)^{2}-12.9 s^{j}\left(\tilde{E}-0.1 \sum_{i=1}^{4} a_{i}\right)\right)$ is the disutility of pollution. ${ }^{15}$

\footnotetext{
${ }^{13}$ This test was originally set up by Scheier and Carver (1985).

${ }^{14}$ It was not possible to completely eliminate pollution in this experiment.

${ }^{15}$ This function has been chosen to ensure enough difference between the two types of players.
} 
Subjects in the tax treatment faced in addition a linear tax on the difference between 10 (the socially optimal contribution) and their level of contribution, with $\tau=0.487$ following equation (5). ${ }^{16}$ Table 1 provides the private and social optima for both types of players.

Table 1: Private and social optima

\begin{tabular}{lcccc}
\hline & $\begin{array}{c}\text { Private optimum } \\
\text { Baseline }\end{array}$ & $\begin{array}{c}\text { Private optimum } \\
\text { Nudge }\end{array}$ & $\begin{array}{c}\text { Private optimum } \\
\text { Tax }\end{array}$ & Social optimum \\
\hline Player A & 0 & $>0$ & 2 & 10 \\
Player B & 3 & $>3$ & 10 & 10 \\
\hline
\end{tabular}

Recall that these equilibria are computed with the regulator's beliefs. Indeed, to compute the exact equilibria, it would have been necessary to know the composition of each groups ex ante. In that case, it would have been necessary to replicate this experiment many times to obtain a sufficiently high number of independent observations. We believe this is not a concern, because we are mainly interested in the impact of each instrument on individuals' decisions. We just want to verify whether we obtain a higher level of contributions with these instruments. Moreover, we are mainly interested in the impact of individuals' sensitivity to the environment on the efficiency of these instruments.

Subjects were given four tables for earnings, expressed in Experimental Currency Units (ECU): one for each player (Player $A$ and $B$ ) in each situation (low level of pollution and high one). The rate of conversion was 40 tokens for 1 euro. Before they took their decision, subjects had the possibility to use a simulator on the computer ${ }^{17}$. Then, subjects had to choose their level of investment. At the end of the period, they were informed about the level of pollution, the total investment made by the group and their earnings for the period.

\footnotetext{
${ }^{16}$ This marginal rate of taxation was not the optimal one for A Players, but can be considered to be the optimal one for B Players because they should theoretically contribute 9.49 tokens. However, the subjects could invest positive integers only. Thus, they should theoretically contribute 10 tokens with this marginal rate.

${ }^{17}$ The simulator was available for 3 minutes. The subjects could choose a level of investment in the environmental account, and the possible gains for both players and both states of nature for this level of investment was displayed on the screen, depending on the other members' investment.
} 


\subsection{Behavioral hypotheses}

According to the model proposed in the previous section, we can expect an increase in the level of contributions under the implementation of the tax and of the nudge. However, we may obtain higher level of contributions with groups of $B$ Players under the implementation of the nudge as they are the most sensitive to environmental matters. Indeed, our hypothesis was that the reaction to the nudge would depend directly on individuals' sensitivity.

Concerning the implementation of the tax, it is similar to the one proposed by Falkinger et al. (2000). More precisely, the authors test a tax/subsidy mechanism proposed by Falkinger (1996): subjects are taxed (subsidized) on the difference between their investment in the public account and the mean investment of the other members of the group. The authors show that the Nash equilibrium is a good predictor of the level of contributions of the subjects. We could thus expect the subjects to contribute at Nash equilibrium level in the tax implementation scenario.

However, the tax implemented in our experiment is on the difference between the subjects' level of investment in the environmental account and the socially optimal investment which is the same for both types of players. As for the nudge, we may assume that the fact we announce that the subjects will be taxed if they contribute less than 10 , may act as an anchor. Moreover, we do not specify that 10 is the best solution for the environment, so that, contrary to the nudge, the tax is not a priori built on environmental sensitivity. As a consequence, the alternative hypothesis is that both types of players will contribute at similar levels in the tax scenario.

\section{$5 \quad$ Results}

In this section, we first present the results of the psychological measures (GEB and LOT$\mathrm{R})$. We then perform tests on the aggregate levels of contribution. Finally, we turn to the analysis of individual decisions.

\subsection{Measurement of environmental sensitivity and optimism}

We first report the results from the GEB test that we used to measure subjects' environmental sensitivity. On the 28 items, the mean score per item was 3.66 ( $\mathrm{SD}=1.29$ ). 
Overall, the GEB scale was found to be acceptable $(\alpha=0.74) .{ }^{18}$ Concerning the LOT-R that we used to measure the subjects' optimism, the mean score per item was 3.39 (SD $=1.08)$. The LOT-R scale was found to be moderately acceptable $(\alpha=0.63) .{ }^{19}$

In the model presented above, one of the assumptions is that environmental sensitivity and optimism are two distinct characteristics. The alternative hypothesis could be that individuals' sensitivity may determine their optimism regarding the risk of pollution. For instance, individuals woth low sensitivity to environmental matters would be highly optimistic concerning the risk of pollution, as the environment is not a priority for them. In such a case, our theoretical predictions would not have been different from Etner et al. (2007, 2009): the most optimistic individuals (being also the least sensitive) would contribute less to environmental quality than the least optimistic individuals (being also the most sensitive).

The correlation between both is very low $(\rho=-0.069)$. Using a Spearman's rank correlation test, we cannot reject the hypothesis that the correlation between sensitivity and optimism is null $(p$-value $=0.447)$.

Result 1: The assumption that environmental sensitivity and optimism are two distinct characteristics is a fair one.

The fact that this assumption is supported is good news for the theoretical model presented in section 3. However, we should keep in mind that the internal consistency of the LOT-R was only moderately acceptable. This could mitigate Result 1.

We can now determine the impact of these two intrinsic characteristics on the individuals' level of contributions. In the model presented in section 3, we have shown that in the absence of outside incentives, it is not possible to establish a complete ranking of individual contributions depending on these two intrinsic characteristics. In table 2, we present the mean individual contributions in the first period depending on the profile of the subjects (in the baseline). We consider the first period because this is the only one

\footnotetext{
${ }^{18}$ Internal consistency in previous studies ranges from $\alpha=0.73$ (Kaiser and Biel (2000)), $\alpha=0.74$ (Kaiser and Wilson (2000)), $\alpha=0.76$ (Corral-Verdugo et al. (2009)), to $\alpha=0.86$ (Scannell and Gifford (2010)).

${ }^{19}$ Internal consistency in previous studies was $\alpha=0.68$ in Glaesmer et al. (2012), and $\alpha=0.58$ in Zenger et al. (2013).
} 
in which individual decisions are made independently. In the next periods, individuals' decisions depend on the history of their group.

We can notice that, whatever the subjects' level of optimism, the higher their environmental sensitivity, the higher their contribution. However, there are no significant differences in the contributions between these profiles (Kruskal-Wallis test, $p$-value $=$ 0.119). Thus, we cannot reject the hypothesis that subjects do not differ in the baseline.

Table 2: Mean individual contributions per profile in the baseline in the first period (standard deviation in parenthesis).

Mean contribution

\begin{tabular}{cc} 
Profile & (St. Dev.) \\
\hline$(v, h)$ & 5.94 \\
& $(2.41)$ \\
17 obs. \\
\hline \multirow{2}{*}{4.33} \\
$(v, l)$ & $(2.97)$ \\
& 15 obs. \\
\hline & 5.80 \\
$(r, h)$ & $(1.92)$ \\
& 5 obs. \\
\hline & 4.17 \\
$(r, l)$ & $(1.15)$ \\
& 7 obs.
\end{tabular}

Again, this result should be considered with precaution for at least two reasons. First, the internal consistency of the LOT-R test being moderately acceptable, the difference in subjects' optimism may be quite small in reality, so that they do not really differ in this characteristic. Second, this public goods game is slightly more difficult to understand in comparison with the classic one. As a consequence, even if we tested the subjects' understanding of the game before it started, some may have played in a random way.

In the next subsection, we draw a clearer a picture analyzing mean contributions during the 15 periods. 


\subsection{Mean contributions}

Mean contributions of the different groups, per treatment, are summarized in table 3. Whatever the treament, groups of $B$ Players contribute more than groups of A Players. Moreover, for groups of $A$ Players, the implementation of the nudge seems to crowd out the level of contributions in comparison to the baseline, contrary to the tax implementation. Groups of $B$ Players increase their level of contributions under the implementation of the nudge in comparison to the baseline, but this increase is even higher under the tax implementation.

Table 3: Mean group contributions per treatment (standard deviation in parenthesis).

\begin{tabular}{cccc}
\hline & Baseline & Nudge & Tax \\
\hline \multirow{2}{*}{ Groups A } & $18.62(5.13)$ & $13.21(8.25)$ & $24.98(6.92)$ \\
& 6 groups & 6 groups & 4 groups \\
\hline \multirow{2}{*}{ Groups B } & $21.31(4.32)$ & $24.37(5.88)$ & $30.98(6.05)$ \\
& 5 groups & 5 groups & 6 groups \\
\hline
\end{tabular}

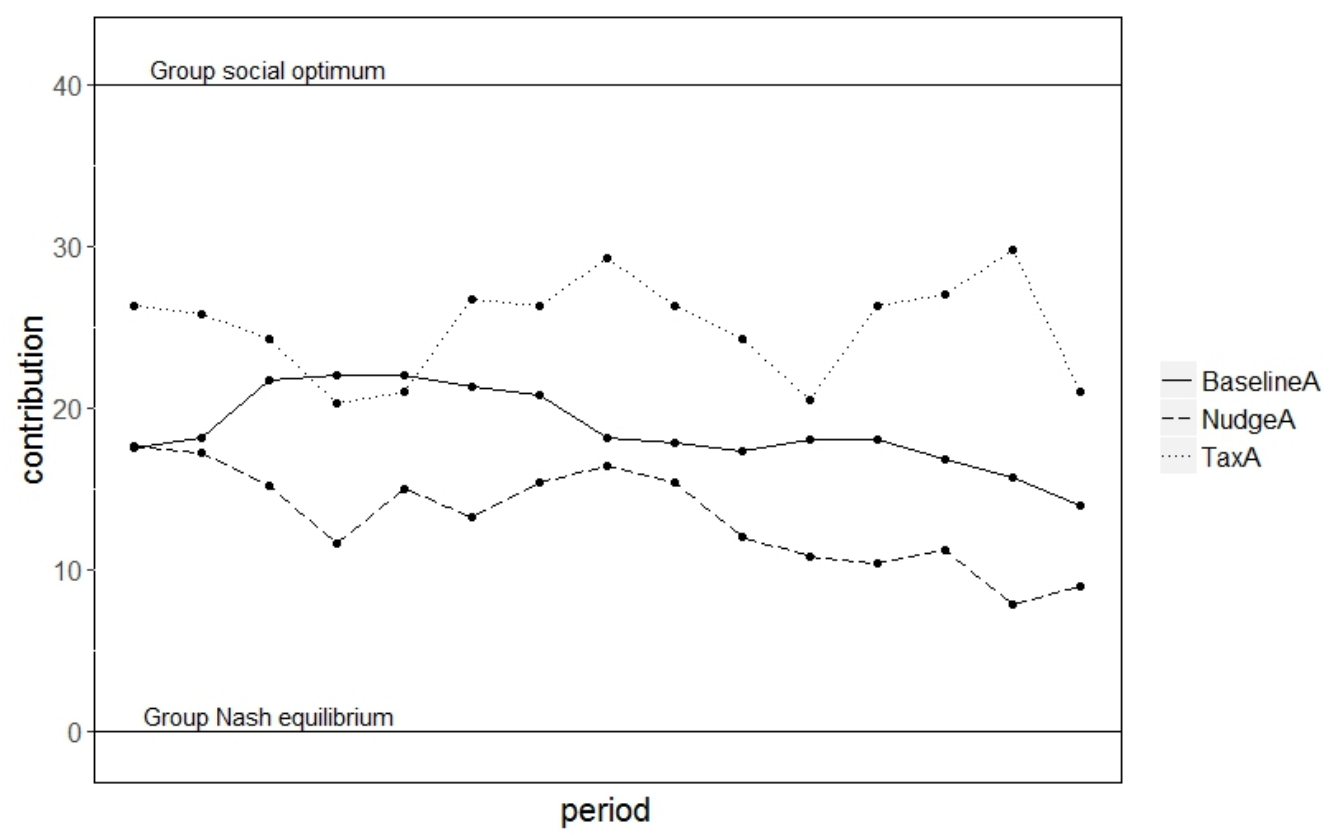

Figure 1: Average group contributions per period (Groups A)

The dynamics of groups' contributions are illustrated in figures 1 and 2 (respectively for groups of $A$ Players and $B$ ). For both types of players, the level of contributions 


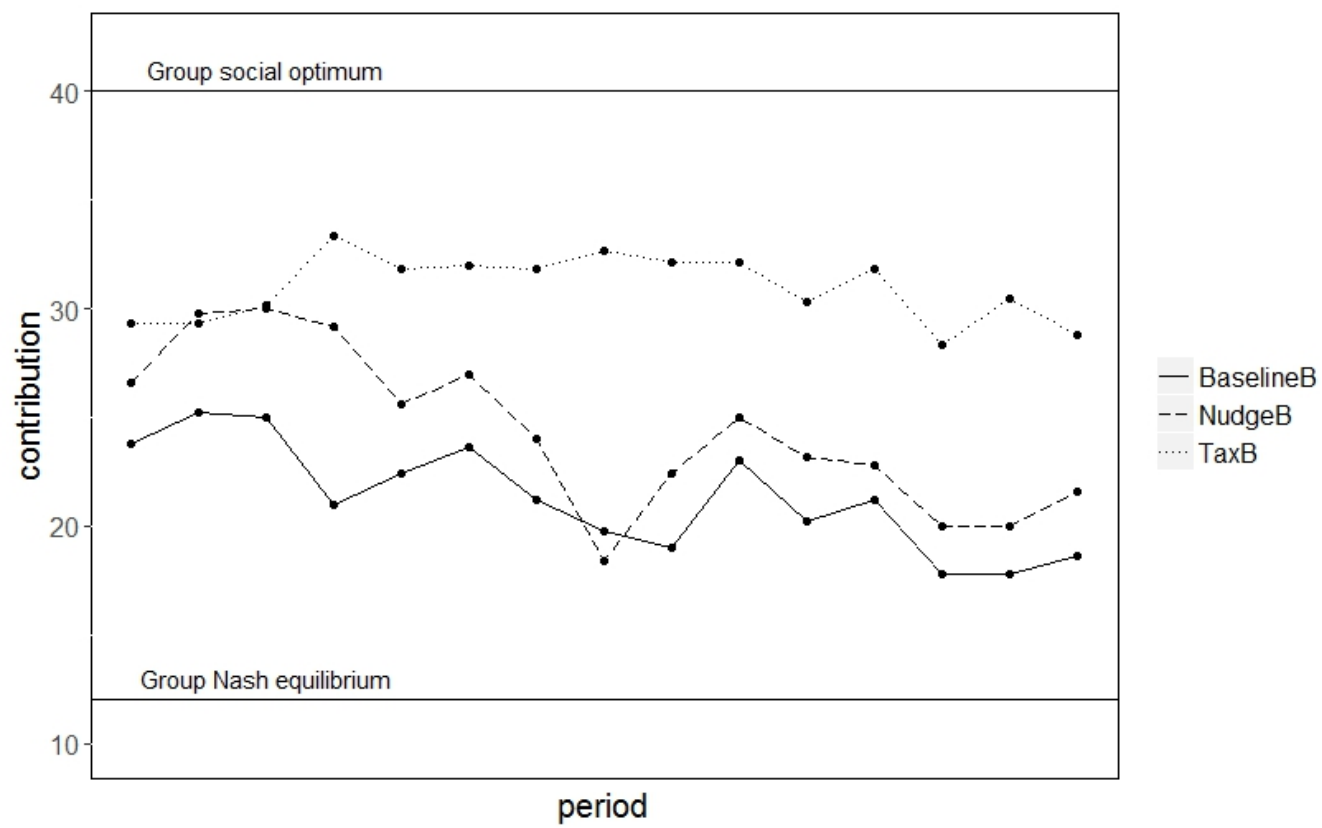

Figure 2: Average group contributions per period (Groups B)

decrease over time in the baseline and under the implementation of the nudge. However, this level of contributions seems to exhibit a constant trend over time under the tax implementation (with a higher variance for groups of $A$ Players).

To confirm these observations, we conduct non-parametric tests on groups' mean contributions. In the baseline, the subjects in groups of $A$ Players contributed less than the subjects in groups of $B$ Players, but this difference is not significant (two-sided MannWhitney rank sum test, $p$-value $=0.120)$. Even if the mean group contribution for $A$ Players is lower under the implementation of the nudge than in the baseline, the difference is not significant (two-sided Mann-Whitney rank sum test, $p$-value $=0.234$ ). For $B$ Players, the implementation of the nudge does not induce an increase of the aggregate level of contributions in comparison to the baseline (two-sided Mann-Whitney rank sum test, $p$-value $=0.144) .{ }^{20}$ Notice that the pattern of contributions differs significantly between groups of $A$ Players and $B$ (two-sided Mann-Whitney rank sum test, $p$-value $=0.012$ ). Thus, the reaction to the nudge seems to depend on environmental sensitivity, given that

\footnotetext{
${ }^{20}$ Our hypothesis was that the nudge would induce an increase in the aggregate level of contributions compared to the level observed in the baseline, thus corresponding to a unilateral test. In that case, the $p$-associated with such a test is 0.072 (marginal increase of the aggregate level of contributions. However, the adapted test is a bilateral one in our case.
} 
the pattern of contributions between these two groups does not differ significantly in the baseline as observed previously.

When considering figure 2, it seems that the nudge has a positive impact for groups of $B$ Players up to the end of the $7^{\text {th }}$ period included. This corresponds to a significant difference in the level of contributions compared to the baseline (two-sided Mann-Whitney rank sum test, $p$-value $=0.012$. Thus, it seems that our nudge is a short-term incentive compared to the tax.

Indeed, in the tax scenario, both types of players contribute more compared to the baseline (significant difference), with a higher and smoother reaction from groups of $B$ Players (two-sided Mann-Whitney rank sum test, $p$-value $=0.042$ for groups of $A$ Players, and $p$-value $=0.008$ for groups of $B$ Players $).{ }^{21}$ Moreover, there is no significant difference between groups of $A$ Players and $B$ (two-sided Mann-Whitney rank sum test, $p$-value $=$ $0.166)$.

Result 2: a) The tax induces a significant increase in contributions compared to the baseline during the 15 periods of treatment. The nudge induces a significant increase only for groups of $\mathrm{B}$ Players during the first 7 periods.

b) The levels of contributions of groups of A Players and B differ significantly under the implementation of the nudge, while they do not under tax implementation.

As explained previously, these two instruments differ for at least two reasons: contrary to the tax, our nudge depends directly on the individuals' environmental sensitivity and, this is efficient only during a given time period. In the next subsection, we analyze the determinants of individual contributions.

\subsection{Individual decisions}

In order to study the determinants of individuals' contributions, we follow the same emprirical strategy proposed by Préget et al. (2016), who estimate a Tobit model with correlated random effects. This method is based on Woolridge (2005) who proposes solutions to estimate nonlinear panel data models.

\footnotetext{
${ }^{21}$ There is little evidence that the tax performs better than the nudge (two-sided Mann-Whitney rank sum test, $p$-value $=0.07$ for $A$ Players, and $p$-value $=0.06$ for $B$ Players $)$.
} 
Indeed, we want to monitor the effect of individuals' contribution in period $t-1$ compared to the contribution in period $t$. Including such a variable may cause endogeneity concerns. ${ }^{22}$ Thus, Wooldridge (2005) proposed to condition the distribution of the nonobserved effect on the initial value (the contribution in the first period in our case, denoted $\alpha_{1}$ ) and on a set of exogenous variables (the level of pollution in previous periods in our case) associated to the vector $\alpha_{2}$.

Subjects could choose any contribution between 0 and 10. Let us denote as $a_{i t}$ subject $i$ 's contribution in period $t$. We thus estimate the following censored dynamic panel model:

$$
a_{i t}= \begin{cases}0 & \text { if } a_{i t}^{*} \leq 0 \\ a_{i t}^{*} & \text { if } 0<a_{i t}^{*}<10 \\ 10 & \text { if } a_{i t}^{*} \geq 10\end{cases}
$$

The latent model is given by

$$
a_{i t}^{*}=\rho a_{i, t-1}+z_{i t} \gamma+\lambda_{i}+v_{i t}
$$

with $\gamma$ being the vector of independent variables, $\lambda_{i}$ a random individual effect and $v_{i t}$ the standard regression error (supposed normally distributed).

The results are summarized in table 4 . In the first model, the variable decision ${ }_{t-1}$ is for individual $i$ 's contribution in the previous period. The variables $t 2$ and $t 3$ are dummies for, respectively, the treatments with nudge and tax. The variables sensitivity and optimism are also dummies, for subjects' sensitivity and optimism. ${ }^{23}$ The regression also includes variables for the period, gender (equal to 1 if the subject is a female), age, background (equal to 1 if the subject studies economics) a dummy volunteer if the subject participates in a charitable association, a variable sport if the subject practices a sporting activity, a variable politics if the subject is part of a political party, and a variable religion if the subject is a catholic.

\footnotetext{
${ }^{22}$ Endogeneity may come from the fact that the choice in period $t$ may be correlated with the decision in period $t-1$.

${ }^{23}$ The variable sensitivity takes the value 1 (subject highly sensitive to the environment) if subject $i$ 's score to the GEB scale was above 104, the mean of the GEB score in the first session. The variable optimism takes the value 1 (subject few optimistic) if subject $i$ 's score to the LOT-R was less or equal to 30 .
} 
Table 4: Tobit estimation.

\begin{tabular}{lccccc}
\hline \multirow{2}{*}{ Variable } & \multicolumn{2}{c}{$(1)$} & & \multicolumn{2}{c}{$(2)$} \\
\cline { 2 - 3 } \cline { 5 - 6 } Contribution in 1st period & $0.500^{* * *}$ & $(1.020)$ & & $0.479^{* * *}$ & $(0.099)$ \\
Decision $_{t-1}$ & $0.177^{* * *}$ & $(0.048)$ & & $0.177^{* * *}$ & $(0.42)$ \\
Period & $-0.122^{* * *}$ & $(0.027)$ & & $-0.122^{* * *}$ & $(0.023)$ \\
t2 & -0.302 & $(0.772)$ & & -1.765 & $(1.094)$ \\
t3 & $1.876^{*}$ & $(1.051)$ & & $1.756^{*}$ & $(0.972)$ \\
Sensitivity & $1.981^{* *}$ & $(0.825)$ & & 1.308 & $(1.038)$ \\
Sensitivity $\times$ t2 & & & & $3.198^{*}$ & $(1.735)$ \\
Pollution & & & & & \\
Optimism & -0.191 & $(0.165)$ & & -0.192 & $(0.184)$ \\
Constant & -0.270 & $(0.577)$ & & -0.290 & $(0.733)$ \\
\hline$\sigma_{\lambda}$ & 0.496 & $(4.021)$ & & 0.517 & $(3.370)$ \\
$\sigma_{v}$ & $1.973^{* * *}$ & $(0.235)$ & & $1.904^{* * *}$ & $(0.226)$ \\
LR $\chi^{2}(17)$ & $2.967^{* * *}$ & $(0.195)$ & & $2.967^{* * *}$ & $(0.182)$ \\
Log-likelihood & $27.587^{* * *}$ & & $27.587^{* * *}$ & \\
Number of individuals & -3520.575 & & -3516.689 & \\
Number of observations & 124 & & & 124 & \\
\hline & 1736 & & 1736 & \\
\hline
\end{tabular}

Standard errors (in parenthesis) are bootstrapped

Significance level: $1 \%\left({ }^{* * *}\right), 5 \%(* *)$ et $10 \%(*)$

We estimated two models. In both models, individual contributions are explained positively by the contribution in the first period (significant at the $1 \%$ level), by the decision in the previous period (significant at the $1 \%$ level), and negatively by the period (significant at the 1\% level). Ledyard (1995) and Chaudhuri (2011) explain that the level of contribution in public goods games decreases over time. One reason is that subjects are imperfect conditional cooperators (Keser and van Winden (2000), Fischbacher et al. (2001)).

In the first model, the treatment with the tax has a positive and significant effect (at the $10 \%$ level) on individual decisions, whatever the subjects' sensitivity. The variable sensitivity has also a positive and significant effect (at the $5 \%$ level). However, the variable optimism has no effect on individual contributions, as for the treatment with the 
nudge. We saw in the previous subsection that the effect of the nudge was not the same on groups of $A$ Players and $B$.

Thus, we estimated a second model in which we included a cross-variable sensitivity $\times$ t2, to capture the effect of being sensitive while being treated with the nudge on individual contributions. The coefficient associated to this variable is positive and significant (at the $10 \%$ level).

Finally, we computed the log-likelihood ratio for each model. This ratio compare the likelihood of the dynamic model with the one of a static one (without the variable decision $_{t-1}$ ). In both cases, the test is significant (at the $1 \%$ level), thus supporting the use of a dynamic model. ${ }^{24}$

Result 3: As expected in the theoretical model, environmental sensitivity is a determinant of the reaction to our nudge.

This result seems to corroborate the predictions of the model proposed by Ouvrard and Spaeter (2016) and in this paper. However, we should keep in mind, when considering this result, that as explained at the beginning of this section that we should not reject the hypothesis that our subjects are not different (as their level of contributions do not differ when considering them according to the two intrinsic characteristics). Notwithstanding, we also explained that this observation may be shaded as subjects may not have had a perfect understanding of the game in the first period.

In the next section, we propose to complement our analysis with a study of the relative efficiency of each instrument.

\section{Efficiency}

Up to now, we have focused on the effects on the level of contributions. We now propose to study the effects of the implementation of the tax and of the nudge on the groups' welfare. Following Spraggon (2002), Cochard et al. (2005) and Willinger et al. (2014), two measures are considered: efficiency (measuring the improvement in the groups' welfare in comparison to the social optimum) and reliability (measuring how an instrument may predict levels of efficiency).

\footnotetext{
${ }^{24}$ The null hypothesis of this test is $H_{0}: \rho=\alpha_{0}=\alpha_{1}=0$, that is to say the model is static.
} 
In the next subsection we analyze the relative efficiency of each instrument. Then, we will study their reliability. The results are discussed in the next section.

\subsection{Efficiency of the tax and of the nudge}

To measure the improvement in welfare due to the implementation of an incentive tool, Spraggon (2002) proposed to consider the efficiency rate. Let us denote as $W^{o}$ the welfare of the group in the absence of any regulation, and $W^{*}$ the welfare of the group at the social optimum. ${ }^{25}$ Lastly, let us denote as $W_{t}$ the observed welfare of the group in period $t$. The efficiency rate in period $t$, denoted as $\epsilon_{t}$, is defined as follows:

$$
\epsilon_{t}=\frac{E\left(W_{t}\right)-E\left(W^{o}\right)}{E\left(W^{*}\right)-E\left(W^{o}\right)} \times 100
$$

If an instrument is calibrated such that individuals should play the socially optimal contribution, then the efficiency rate should be equal to $100 \%$.

In table 5 we reported the average efficiency rates (in \%) per group and per treatment and the asymptotic efficiency rates. ${ }^{26}$ As explained in Cochard et al. (2005) and Willinger et al. (2014), averages do not take into account the possibility that subjects learn over time (an average gives the same weight to each period). Similarly to Noussair et al. (1995), these authors estimated asymptotic values according to the following model:

$$
\epsilon_{i t}=\epsilon^{\infty}+\epsilon^{0} \frac{1}{t}+\mu_{i}+v_{i t}
$$

with the random variable $\mu_{i}$ that captures random effects at the level of the group (assumed normally distributed) and $v_{i t}$ is an error term. $\epsilon^{\infty}$ is the asymptotic efficiency when $t$ tends to infinity. The closer $\epsilon^{\infty}$ is to 100 , the more robust is the instrument. Finally, $\epsilon^{0}+\epsilon^{\infty}$ is the efficiency in the first period.

The average efficiency rate in the baseline for groups of $A$ Players is significantly larger than the one for groups of $B$ Players (Mann-Whitney-Wilcoxon two sided test, $p$-value $=$ 0.008). We saw in the previous section that the level of contributions between these two

\footnotetext{
${ }^{25}$ The welfare of the group is computed with equation (4). In the absence of any regulation, the welfare of a group of $A$ Players (each member investing 0 in the environmental account) is $1920 \mathrm{ECU}$, and it is 1414.86 ECU for a group of $B$ Players. At the social optimum, the welfare of a group of $A$ Players is $2086 \mathrm{ECU}$, and it is $1647.40 \mathrm{ECU}$ for a group of $B$ Players.

${ }^{26}$ Asymptotic efficiency rates correspond to the efficiency rate that shoud be observed in the long run following the implementation of an instrument.
} 
Table 5: Average efficiency rates (in \%) per group and per treatment and asymptotic efficiency rates (in bold).

\begin{tabular}{cccc}
\hline & Baseline & Nudge & Tax \\
\hline \multirow{2}{*}{ Groups A } & 62.68 & 44.27 & 75.97 \\
& $\mathbf{6 1 . 4 4}$ & $\mathbf{3 9 . 0 5}$ & $\mathbf{7 4 , 8 3}$ \\
\hline \multirow{2}{*}{ Groups B } & 37.79 & 47.89 & 71.19 \\
& $\mathbf{3 2 . 5 9}$ & $\mathbf{4 1 . 1 3}$ & $\mathbf{7 2 . 4 9}$ \\
\hline
\end{tabular}

groups of players does not differ significantly in the baseline. However, while groups of $A$ Players theoretically do not contribute in the baseline (Nash equilibrium), groups of $B$ Players theoretically contribute a total of 12 tokens. This may explain why the efficiency rate is higher in the baseline for groups of A Players.

As expected from the previous section, the average efficiency rates are the highest under the tax sceanrio for both types of groups and significantly differ from those observed in the baseline (Mann-Whitney-Wilcoxon two sided test, $p$-value $=0.070$ for groups of $A$ Players and $p$-value $=0.006$ for groups of $B$ Players), as well from those observed under the nudge scenario (Mann-Whitney-Wilcoxon two sided test, $p$-value $=0.020$ for groups of $A$ Players and $p$-value $=0.035$ for groups of $B$ Players $)$.

Implementation of the nudge reduces significantly groups' welfare for A Players in comparison with the baseline (Mann-Whitney-Wilcoxon two sided test, $p$-value $=0.055$ ), but does not affect the welfare of groups of $B$ Players (Mann-Whitney-Wilcoxon two sided test, $p$-value $=0.296)$. We could expect these results from the previous section. Notwithstanding, the efficiency analysis helps us to refine our results as we detect a decrease in the welfare of the group for A Players, that was not detected in the previous section. We discuss this point in the next section.

To confirm these observations, we estimated asymptotic efficiency rates. The results are reported in table 6.

We report the tests on differences between coefficients in the appendix. In particular, we show that asymptotic efficiency is significantly higher for both types of players, in the tax scenario than in the baseline and with the nudge.

We can also test whether asymptotic efficiency rate coefficients differ for a given instrument between the two types of players. We obtain that the asymptotic efficiency rate 
Table 6: Random-effects GLS regression of efficiency rates.

\begin{tabular}{lccccccccc}
\hline & \multicolumn{2}{c}{ Baseline } & & \multicolumn{2}{c}{ Nudge } & & \multicolumn{2}{c}{ Tax } \\
\cline { 2 - 3 } \cline { 8 - 9 } \cline { 8 - 9 } Sequence & Gr. A & Gr. B & & Gr. A & Gr. B & & Gr. A & Gr. B \\
\hline$\epsilon^{0}(\%)$ & 5.61 & 23.53 & & 23.58 & 30.65 & & 5.14 & -5.83 \\
St. Err. & 0.058 & 0.076 & & 0.077 & 0.097 & & 0.060 & 0.066 \\
p-value & 0.336 & 0.002 & & 0.002 & 0.002 & & 0.393 & 0.377 \\
$\epsilon^{\infty}(\%)$ & 61.44 & 32.59 & & 39.05 & 41.13 & & 74.83 & 72.49 \\
St. Err. & 0.033 & 0.036 & & 0.086 & 0.055 & & 0.055 & 0.068 \\
p-value & 0.000 & 0.000 & & 0.000 & 0.000 & & 0.000 & 0.000 \\
\hline
\end{tabular}

is significantly higher in the baseline for groups of $A$ Players than for groups of $B$ Players $(p$-value $=0.000) .{ }^{27}$ However, we do not detect any difference between the two types of players under the implementation of each instrument ( $p$-value $=0.840$ with the nudge, and $p$-value $=0.787$ with the tax).

Result 4: The tax and the nudge induce different rates of efficiency. In particular,

a) the tax is the instrument which induces the highest efficiency.

b) the nudge has a negative impact on the welfare of groups of A Players.

This result seems to indicate that regulators should target individuals when implementing a nudge policy based on the disclosure of some information (aimed, in this paper, at making those individuals who show an interest in the public good react to environmental issues).

\subsection{Reliability of the instruments}

Cochard et al. (2005) and Willinger et al. (2014) propose to measure reliability in absolute terms (with the variability of group contributions) and in relative terms (with the variability of efficiency). The inter-periodic variability of contributions measures whether contributions at the level of the group vary over time. If an instrument is robust then we should observe a value close to 0 . It is given by:

$$
\frac{\left(\sum_{t=1}^{15} \frac{\left(A_{t}-\bar{A}_{t}\right)^{2}}{15}\right)^{0.5}}{\bar{A}_{t}}
$$

\footnotetext{
${ }^{27}$ The method is detailed in the appendix.
} 
where $A_{t}$ is the sum of contributions of a given group in period $t$, and $\bar{A}_{t}$ is the mean contribution at the level of the group over the 15 periods.

We also consider the inter-group variability of contributions. It measures, for each period, the variation in terms of contributions at the level of the group, in comparison with the mean group contribution (for all groups). It is given by:

$$
\frac{\left(\sum_{i=1}^{I} \frac{\left(A_{i}-\bar{A}_{i}\right)^{2}}{I}\right)^{0.5}}{\bar{A}_{i}}
$$

where $A_{i}$ is the sum of contributions in group $i$, and $\bar{A}_{i}$ is the average of groups' contributions.

Finally, the inter-periodic variability of efficiency measures the evolution of efficiency over time for a given group. We denote it $\left|\Delta \epsilon_{i t}\right|$ and it is equal to $\left|\epsilon_{i t}-\epsilon_{i t-1}\right|$. The shorter the gap between two periods in absolute value is, the more robust the instrument.

\subsubsection{Inter-periodic variability of contributions}

We present the inter-periodic variability of contributions in table 7 . In the baseline, we do not detect significant differences in the inter-periodic variabilities of contributions between groups of $A$ Players and $B$ (Mann-Whitney-Wilcoxon bilateral test, $p$-value $=$ 0.315). In comparison with the baseline, the inter-periodic variability of contributions significantly increases in groups of A Players following the implementation of the nudge (Mann-Whitney-Wilcoxon bilateral test, $p$-value $=0.037$ ), but it does not differ with the tax (Mann-Whitney-Wilcoxon bilateral test, $p$-value $=0.337$ ). For groups of B Players, the inter-periodic variability of contributions with the nudge does not differ from the baseline (Mann-Whitney-Wilcoxon bilateral test, $p$-value $=0.676$ ), but decreases significantly with the tax in comparison to the baseline (Mann-Whitney-Wilcoxon bilateral test, $p$-value $=0.083)$.

Table 7: Inter-periodic variability of contributions (in \%) per group and per treatment.

\begin{tabular}{cccc} 
& Baseline & Nudge & Tax \\
\hline Groups A & 23.91 & 45.71 & 18.83 \\
Groups B & 18.77 & 21.75 & 12.46 \\
\hline
\end{tabular}




\subsubsection{Inter-group variability of contributions}

In table 8 , we present the inter-group variability of contributions. In the baseline, it is significantly lower in groups of $B$ Players than in groups of $A$ Players (Mann-WhitneyWilcoxon bilateral test, $p$-value $=0.075$ ). There is still this significant difference between both types of players in the tax scenario (Mann-Whitney-Wilcoxon bilateral test, $p$-value $=0.013$ ) and in the nudge scenario (Mann-Whitney-Wilcoxon bilateral test, $p$-value $=$ $0.000)$.

Considering the implementation of the instruments for a same type of group, the tax does not induce significant differences with the baseline for both types (Mann-WhitneyWilcoxon bilateral test, $p$-value $=0.534$ for $A$ Players and $p$-value $=0.384$ for B Players , but the nudge increases significantly the inter-group variability of contributions for $A$ Players only (Mann-Whitney-Wilcoxon bilateral test, $p$-value $=0.000$ for A Players and $p$-value $=0.694$ for $B$ Players $).$

Table 8: Inter-group variability of contributions (in \%) per group and per treatment.

\begin{tabular}{cccc} 
& Baseline & Nudge & Tax \\
\hline Groups A & 23.68 & 58.64 & 24.47 \\
Groups B & 16.24 & 18.74 & 18.71 \\
\hline
\end{tabular}

To confirm our observations, we estimated the asymptotic inter-periodic reliability. The results are presented in table 9 .

Table 9: Random-effects GLS of asymptotic inter-periodic reliability..

\begin{tabular}{lccccccccc}
\hline & \multicolumn{2}{c}{ Baseline } & & \multicolumn{2}{c}{ Nudge } & & \multicolumn{2}{c}{ Tax } \\
\cline { 2 - 3 } \cline { 8 - 9 } Sequence & Gr. A & Gr. B & & Gr. A & Gr. B & & Gr. A & Gr. B \\
\hline$\Delta^{0}(\%)$ & -19.34 & -4.18 & & -9.92 & -18.50 & & -23.63 & 0.53 \\
St. Err. & 0.063 & 0.121 & & 0.107 & 0.131 & & 0.095 & 0.108 \\
p-value & 0.002 & 0.729 & & 0.352 & 0.158 & & 0.013 & 0.961 \\
$\Delta^{\infty}(\%)$ & 12.74 & 14.55 & & 14.13 & 19.96 & & 14.75 & 13.71 \\
St. Err. & 0.016 & 0.025 & & 0.022 & 0.032 & & 0.021 & 0.039 \\
p-value & 0.000 & 0.000 & & 0.000 & 0.000 & & 0.000 & 0.000 \\
\hline
\end{tabular}

The tests on the differences between the estimated coefficients are presented in the appendix, and we find no significant differences between types of players (for a given 
instrument), or between instruments and the baseline (for a given type of player).

\subsubsection{Inter-periodic variability of efficiency}

We detail inter-periodic variability of efficiency in table 10. No significant difference is detected between groups of $A$ Players and $B$ for a given treatment (Mann-WhitneyWilcoxon bilateral test, $p$-value $=0.121$ in the baseline, $p$-value $=0.144$ for the treatment with the nudge, and $p$-value $=0.456$ for the treatment with the tax).

Table 10: Inter-periodic variability of efficiency (in \%) per group and per treatment.

\begin{tabular}{cccc} 
& Baseline & Nudge & Tax \\
\hline Groups A & 12.29 & 16.14 & 10.90 \\
Groups B & 16.18 & 20.52 & 13.77 \\
\hline
\end{tabular}

We report other tests on the difference between the inter-periodic variability of efficiency, for a given type of player in the appendix. No significant differences are found among instruments. This seems to indicate that no instrument dominates the other one regarding the robustness of efficiency over time.

\subsubsection{Inter-group asymptotic efficiency}

We end our analysis with the study of inter-group asymptotic efficiency, estimated with the following model:

$$
S G_{t}=S G^{\infty}+S G^{0} \frac{1}{t}+v_{t}
$$

with $S G_{t}$ the inter-group variability of efficiency in period $t, v_{t}$ is an error term following an $\operatorname{AR}(1)$ process with $v_{t}=\rho v_{t-1}+\lambda_{t}$, and $\lambda_{t}$ is an independently and identically distributed residual. The results are presented in table 11.

We report the results of the comparison of the differences between the estimates obtained in this regression in the appendix. For groups of A Players, the only significant difference we detect is between asymptotic inter-group variabilities of efficiency under the implementation of the nudge and of the tax $(p$-value $=0.047)$. For groups of B Players, we confirm that the asymptotic inter-group variability of efficiency increases both under the implementation of the nudge and of the tax in comparison to the baseline ( $p$-value $=$ 0.056 for the nudge, and $p$-value $=0.039$ for the tax) 
Table 11: Estimates of the asymptotic inter-group variability of efficiency.

\begin{tabular}{lccccccccc}
\hline & \multicolumn{2}{c}{ Baseline } & & \multicolumn{2}{c}{ Nudge } & & \multicolumn{2}{c}{ Tax } \\
\cline { 2 - 3 } \cline { 8 - 9 } Sequence & Gr. A & Gr. B & & Gr. A & Gr. B & & Gr. A & Gr. B \\
\hline$S G^{0}(\%)$ & -12.59 & -5.00 & & -4.68 & -14.29 & & -5.82 & -4.89 \\
St. Err. & 0.194 & 0.049 & & 0.203 & 0.083 & & 0.072 & 0.073 \\
p-value & 0.515 & 0.305 & & 0.818 & 0.086 & & 0.420 & 0.504 \\
$S G^{\infty}(\%)$ & 15.59 & 15.92 & & 24.31 & 21.47 & & 14.95 & 22.38 \\
St. Err. & 0.032 & 0.021 & & 0.043 & 0.020 & & 0.019 & 0.023 \\
p-value & 0.000 & 0.000 & & 0.000 & 0.000 & & 0.000 & 0.000 \\
\hline
\end{tabular}

Result 5: For groups of A Players, there is little evidence that the tax dominates the nudge. For groups of B Players, neither instrument dominates the other.

From this section, we may conclude that the tax is the most efficient instrument. The nudge is less efficient, but as robust as the tax for groups of $B$ Players. Moreover, it seems necessary to target individuals when implementing a nudge like the one we studied, because we found that the nudge may decrease the welfare of groups of individuals with low sensitivity to environmental matters.

\section{Discussion and conclusion}

The experiment proposed in this paper was set up to test the theoretical model proposed by Ouvrard and Spaeter (2016). In particular, this experiment allows for a direct comparison of the effects of a nudge and of a tax to increase individual contributions to environmental quality. The public goods game we proposed differs from the classic one (Ledyard (1995), Chaudhuri (2011)) as we took into account the subjects' environmental sensitivity. ${ }^{28}$ The results we obtained may guide policymakers when proposing nudge policies, as our instruments differ in two dimensions.

First, according to the results we obtained, it seems that the reaction to the nudge we proposed depends on individuals' sensitivity to environmental matters, contrary to the tax. This result goes in the same direction as proposed by Ouvrard and Spaeter (2016) in their theoretical model. This result also shares some similarities with those of Marks

\footnotetext{
${ }^{28}$ Optimism was elicited ex post.
} 
and al. (1999) and Croson and Marks (2001): suggested play is efficient with subjects who differ in their valuation of the public good. ${ }^{29}$

From a public policy point of view, it seems that the implementation of such a nudge requires that the regulator first targets the individuals. Indeed, in the previous section we highlighted a crowding-out of the welfare of groups of subjects with low sensitivity to environmental matters under the implementation of the nudge. In existing literature, a similar effect has already been observed for monetary incentives. Frey (1992) argues that the use of monetary incentives may crowd out individuals' environmental ethics. Bénabou and Tirole $(2003,2006)$ propose models to study the effect of a monetary incentive on individuals' motivation to undertake an action.

In our experiment, the argument is different since we do not observe such an effect with the tax but with the nudge (with the least sensitive individuals). In our case, the hypothesis could be the following: suggesting to an agent to act in a given direction (such as investing in the environmental account in our experiment), when this agent has little interest in the concerned outcome, would reinforce the lack of concern of this agent in the outcome.

Second, when our nudge induces a significant increase of individual contributions (with the most sensitive individuals), the effects of our nudge vanish over time, contrary to the tax. This suggests that our nudge may be a short-term incentive only, thus differing to the reults obtained in the field (Schultz et al. (2007), Nolan et al. (2008), Goldstein et al. (2008), Allcott (2011), Ayres et al. (2013), Costa and Kahn (2013), Ferraro and Price (2013)). Two reasons may explain this difference. Firstly, our nudge is different from the one implemented in these studies, which is based on social comparisons. Second, we oppose results obtained in the laboratory with results obtained in the field. Even if lab experiments can teach us a lot about subjects' behavior, it is artificial and cannot replace a field experiment with real agents (Harrisson and List (2004)). In particular, we asked subjects in this experiment to imagine that they were facing pollution. This could be a limit of our experiment. Moreover, eliciting the subjects' environmental sensitivity at the beginning of the experiment may have influenced some subjects to act after answering the questionnaire.

In our experiment, the effects of our nudge started to vanish in period 8. In another

\footnotetext{
${ }^{29}$ In our case, subjects differ in their valuation of the public bad (pollution).
} 
experiment, we could consider the implementation of a new nudge in period 8 in order to make the subjects continue the effort they have engaged.

A last result should be discussed as, contrary to the predictions in Ouvrard and Spaeter (2016), we were not able to rank the level of contributions according to the two intrinsic characteristics (optimism and environmental sensitivity) in the baseline. This may be due to our protocol, given that we elicited optimism at the end of the public goods game. It may also be due to the fact that we used the first period of the game (the only one that gave us independent observations). However, as we explained previously, at this point of the game some subjects may not have entirely understood the rules. Thus, they may have played randomly. In any case, we did not find evidence in the analysis of individual decisions that optimism was a determinant of the level of contributions.

In sum, the results obtained in this experiment seem to corroborate the predictions obtained in Ouvrard and Spaeter (2016). As in Delaney and Jacobson (2016), the implementation of nudges gives interesting results. However, in this paper we highlighted two major differences with a tax. First, our nudge is not efficient with all individuals. In particular, it seems necessary to target individuals to avoid a potential crowding-out of welfare. Second, contrary to the tax, when efficient, the effects of our nudge do not last over time. Other studies may try to implement another nudge to make individuals pursue their efforts. Moreover, our nudge should be tested in the field to confirm the results obtained in this experiment, and to provide a guideline for policy makers. 


\section{Appendix}

\section{A) Proofs}

\section{Proof of Proposition 1}

i) The first order condition of a regulator who has incomplete information on individuals' risk perception, but has information on individuals' environmental sensitivity, is given by

$$
-u^{\prime}\left(w-a^{*}\right)+\sum_{i}^{N}\left(b^{\prime}(A)\left(q d_{P}\left(\underline{P}, s^{j}\right)+(1-q) d_{P}\left(\bar{P}, s^{j}\right)\right)\right)=0
$$

with $a^{*}$ being the socially optimal contribution. The private first order condition is given by (3). Substracting (15) from (3), both being evaluated in $a^{*}$, gives

$$
b^{\prime}(A)\left(\pi_{i} d_{P}\left(\underline{P}, s^{j}\right)+\left(1-\pi_{i}\right) d_{P}\left(\bar{P}, s^{j}\right)\right)-\sum_{i}^{N}\left(b^{\prime}(A)\left(q d_{P}\left(\underline{P}, s^{j}\right)+(1-q) d_{P}\left(\bar{P}, s^{j}\right)\right)\right)
$$

or equivalently

$$
b^{\prime}(A)\left(\pi_{i}-q\right)\left(d_{P}\left(\underline{P}, s^{j}\right)+d_{P}\left(\bar{P}, s^{j}\right)\right)-\sum_{-i}^{N-1}\left(b^{\prime}(A)\left(q d_{P}\left(\underline{P}, s^{j}\right)+(1-q) d_{P}\left(\bar{P}, s^{j}\right)\right)\right)
$$

with $-i$ for all individuals except $i$. This expression is negative as $d_{p p} \geq 0$. And finally, $a_{i, j}^{p}<a^{*}$

ii) Let us consider (3) for individuals $(v, h)$ and $(r, l)$. Substracting the former from the latter, both evaluated in $a_{r, l}^{p}$, gives after simplification:

$$
b^{\prime}(A)\left(r d_{P}\left(\underline{P}, s^{l}\right)+(1-r) d_{P}\left(\bar{P}, s^{l}\right)\right)-b^{\prime}(A)\left(v d_{P}\left(\underline{P}, s^{h}\right)+(1-v) d_{P}\left(\bar{P}, s^{h}\right)\right)
$$

Rearranging the terms we get:

$$
b^{\prime}(A)\left(r\left(d_{P}\left(\underline{P}, s^{l}\right)-d_{P}\left(\bar{P}, s^{l}\right)\right)+v\left(d_{P}\left(\bar{P}, s^{h}\right)-d_{P}\left(\underline{P}, s^{h}\right)\right)+d_{P}\left(\bar{P}, s^{l}\right)-d_{P}\left(\bar{P}, s^{h}\right)\right)
$$

with $r\left(d_{P}\left(\underline{P}, s^{l}\right)-d_{P}\left(\bar{P}, s^{l}\right)\right)<0$ by convexity of the function $d($.) with respect to $P$, $v\left(d_{P}\left(\bar{P}, s^{h}\right)-d_{P}\left(\underline{P}, s^{h}\right)\right)>0$ following the same argument, and $d_{P}\left(\bar{P}, s^{l}\right)-d_{P}\left(\bar{P}, s^{h}\right)<0$ because $d_{P_{s} j}>0$ by assumption. And finally, the sign of (16) is undetermined.

Following the same steps for individuals $(v, l)$ and $(r, l)$, we show that it is not possible to rank their level of contributions against each other. 


\section{Proof of Proposition 2}

i) Let us consider individuals $(r, l)$ and $(v, h)$. Their first order conditions in the absence of outside incentives are given by (3). Assume that both contribute the same in the absence of outside incentives. From Proposition 1, it is the case if

$$
b^{\prime}(A)\left(v \left(d_{P}\left(\bar{P}, s^{h}\right)-d_{P}\left(\underline{P}, s^{h}\right)-r\left(d_{P}\left(\bar{P}, s^{l}\right)-d_{P}\left(\underline{P}, s^{l}\right)+d_{P}\left(\bar{P}, s^{l}\right)-d_{P}\left(\bar{P}, s^{h}\right)\right)=0\right.\right.
$$

Let us now consider the first order condition under the implementation of a tax. For individual $\left(\pi_{i}, s^{j}\right)$ it is given by equation (6). Substracting this first order condition for individual $(v, h)$ from the first order condition for individual $(r, l)$, both being evaluated at $a_{r, l}^{t}$ gives

$$
b^{\prime}(A)\left(v \left(d_{P}\left(\bar{P}, s^{h}\right)-d_{P}\left(\underline{P}, s^{h}\right)-r\left(d_{P}\left(\bar{P}, s^{l}\right)-d_{P}\left(\underline{P}, s^{l}\right)+d_{P}\left(\bar{P}, s^{l}\right)-d_{P}\left(\bar{P}, s^{h}\right)\right)\right.\right.
$$

We made the assumption that $d_{P s^{j}}=0$, which implies that $d_{P}\left(P, s^{j}\right)$ is additive in $P$ and $s^{j}$. We thus have $d_{P}\left(\bar{P}, s^{l}\right)-d_{P}\left(\bar{P}, s^{h}\right)$ which is constant in $a_{i, j}$ for all $\left(\pi_{i}, s^{j}\right)$.

If $d_{P P P}=0$, then $v\left(d_{P}\left(\bar{P}, s^{h}\right)-d_{P}\left(\underline{P}, s^{h}\right)-r\left(d_{P}\left(\bar{P}, s^{l}\right)-d_{P}\left(\underline{P}, s^{l}\right)\right.\right.$ is constant in $a_{i, j}$. Thus,

$$
b^{\prime}(A)\left(v \left(d_{P}\left(\bar{P}, s^{h}\right)-d_{P}\left(\underline{P}, s^{h}\right)-r\left(d_{P}\left(\bar{P}, s^{l}\right)-d_{P}\left(\underline{P}, s^{l}\right)+d_{P}\left(\bar{P}, s^{l}\right)-d_{P}\left(\bar{P}, s^{h}\right)\right)=0\right.\right.
$$

and $a_{r, l}^{t}=a_{v, h}^{t}$.

If $d_{P P P}<0$, then the group of terms $v\left(d_{P}\left(\bar{P}, s^{h}\right)-d_{P}\left(\underline{P}, s^{h}\right)-r\left(d_{P}\left(\bar{P}, s^{l}\right)-d_{P}\left(\underline{P}, s^{l}\right)\right.\right.$ is higher under the implementation of a tax than in the absence of incentive. We thus have

$$
b^{\prime}(A)\left(v \left(d_{P}\left(\bar{P}, s^{h}\right)-d_{P}\left(\underline{P}, s^{h}\right)-r\left(d_{P}\left(\bar{P}, s^{l}\right)-d_{P}\left(\underline{P}, s^{l}\right)+d_{P}\left(\bar{P}, s^{l}\right)-d_{P}\left(\bar{P}, s^{h}\right)\right)>0\right.\right.
$$

and $a_{r, l}^{t}<a_{v, h}^{t}$.

If $d_{P P P}>0$, then the group of terms $v\left(d_{P}\left(\bar{P}, s^{h}\right)-d_{P}\left(\underline{P}, s^{h}\right)-r\left(d_{P}\left(\bar{P}, s^{l}\right)-d_{P}\left(\underline{P}, s^{l}\right)\right.\right.$ is lower under the implementation of a tax than in the absence of incentive. We thus have

$$
b^{\prime}(A)\left(v \left(d_{P}\left(\bar{P}, s^{h}\right)-d_{P}\left(\underline{P}, s^{h}\right)-r\left(d_{P}\left(\bar{P}, s^{l}\right)-d_{P}\left(\underline{P}, s^{l}\right)+d_{P}\left(\bar{P}, s^{l}\right)-d_{P}\left(\bar{P}, s^{h}\right)\right)>0\right.\right.
$$

and $a_{r, l}^{t}>a_{v, h}^{t}$.

The proofs for Points ii) and iii) follow the same steps as in the proof of Point i). 


\section{Proof of Proposition 3}

i) The first order condition for individual $\left(\pi_{i}, s^{j}\right)$ is given by (3). When a nudge is implemented, it is given by (8). Substracting (8) from (3), both being evaluated at $a_{i, j}^{p}$, gives after simplification

$$
g_{a_{i, j}}\left(a_{i, j}^{p}-a^{*} \mid s^{j}\right)
$$

which is negative. Indeed by assumption $g_{a_{i, j}}\left(a_{i, j}^{n}-a^{*} \mid s^{j}\right)<0$. Finally $a_{i, j}^{n}>a_{i, j}^{p}$.

ii) Let us assume that individuals $(v, h)$ and $(r, l)$ contribute the same level of contributions, both in the initial setting and under the implementation of the tax (this is possible according to Point ii) of Proposition 2). According to the previous proof, the difference between the first order condition of the initial setting and the one with the nudge is $g_{a_{i, j}}\left(a_{v, h}^{n}-a^{*} \mid s^{h}\right)$ for individual $(v, h)$, and $g_{a_{i, j}}\left(a_{r, l}^{n}-a^{*} \mid s^{l}\right)$ for individual $(r, l)$.

We have by assumption that $g_{a_{i, j} s^{j}}\left(. \mid s^{j}\right)<0$ for a same distance. And finally, $a_{v, h}^{n}>$ $a_{r, l}^{n}$.

\section{B) Supplementary tests (efficiency)}

\section{Tests on the coefficients of the asymptotic efficiency rates}

To test whether the coefficients of the asymptotic efficiency rates obtained with the random-effects GLS regression significantly differ, we follow the method proposed by Cochard et al. (2005). In particular, to test whether the coefficients $\epsilon_{\text {baseline }}^{\infty}$ and $\epsilon_{\text {nudge }}^{\infty}$ differ, we compute the following statistic:

$$
z=\frac{\left(\epsilon_{\text {baseline }}^{\infty}-\epsilon_{\text {nudge }}^{\infty}\right)}{\left(S_{\text {baseline }}^{2}-S_{\text {nudge }}^{2}\right)^{0.5}}
$$

with $S_{\text {baseline }}$ and $S_{\text {nudge }}$ the standard errors of the coefficients $\epsilon_{\text {baseline }}^{\infty}$ and $\epsilon_{\text {nudge }}^{\infty}$. The results are reported in tables 12 and 13 .

Table 12: p-values of the tests on differences between coefficients of asymptotic efficiency (groups of Players A).

\begin{tabular}{lcc}
\hline & Baseline A & Nudge A \\
\hline Nudge A & 0.015 & \\
Tax A & 0.037 & 0.000 \\
\hline
\end{tabular}


Table 13: p-values of the tests on differences between coefficients of asymptotic efficiency (groups of Players B).

\begin{tabular}{lcc}
\hline & Baseline B & Nudge B \\
\hline Nudge B & 0.194 & \\
Tax B & 0.000 & 0.000 \\
\hline
\end{tabular}

Tests on the coefficients of the asymptotic inter-periodic reliability

Table 14: $p$-values of the tests on differences between coefficients of asymptotic interperiodic reliability (groups of Players A).

\begin{tabular}{lcc}
\hline & Baseline & Nudge \\
\hline Nudge & 0.610 & \\
Tax & 0.447 & 0.841 \\
\hline
\end{tabular}

Table 15: p-values of the tests on differences between coefficients of asymptotic interperiodic reliability (groups of Players B).

\begin{tabular}{lcc}
\hline & Baseline & Nudge \\
\hline Nudge & 0.184 & \\
Tax & 0.857 & 0.215 \\
\hline
\end{tabular}

Tests on the coefficients of the inter-periodic variability of efficiency

Table 16: p-values of Mann-Whitney-Wilcoxon bilateral test on the inter-periodic variability of efficiency (Groups of Players A).

\begin{tabular}{lcc}
\hline & Baseline & Nudge \\
\hline Nudge & 0.121 & \\
Tax & 0.915 & 0.111 \\
\hline
\end{tabular}


Table 17: p-values of Mann-Whitney-Wilcoxon bilateral test on the inter-periodic variability of efficiency (Groups of Players B).

\begin{tabular}{lcc}
\hline & Baseline & Nudge \\
\hline Nudge & 0.296 & \\
Tax & 0.648 & 0.235 \\
\hline
\end{tabular}

\section{Tests on the coefficients of the asymptotic inter-group reliability}

Table 18: p-values of the tests on differences between coefficients of asymptotic inter-group reliability (groups of Players $A$ ).

\begin{tabular}{lcc}
\hline & Baseline & Nudge \\
\hline Nudge & 0.103 & \\
Tax & 0.865 & 0.047 \\
\hline
\end{tabular}

Table 19: p-values of the tests on differences between coefficients of asymptotic inter-group reliability (groups of Players $B$ ).

\begin{tabular}{lcc}
\hline & Baseline & Nudge \\
\hline Nudge & 0.056 & \\
Tax & 0.039 & 0.764 \\
\hline
\end{tabular}




\section{C) Instructions and questionnaires}

\section{Instructions (nudge treatment)}

\section{Welcome}

You are going to participate in an experiment on decision-making. The rules are simple. If you follow them carefully and if you make good decisions, you may obtain considerable earnings.

All your decisions will be treated anonymously. You will indicate your decisions on the computer to which you have been assigned.

This experiment comprises two stages. These instructions are for the first one. You will receive the instructions for the second stage after the end of the first one. Your payment will be equal to the sum of your earnings in these two stages. At the end of the experiment we will call you individually for your payment.

From now on, we ask you not to talk anymore. If you have any questions, please raise your hand and an experimenter will come to answer you privately.

\section{Instructions of the first stage}

In this stage, we ask you to give your opinion on 28 affirmations. These are affirmations to better know about you. There are no good or bad answers. Try to answer taking into account your own way of life.

At the end of this stage you will be paid 5 euros. This payment is fixed and does not depend on your answers. Answer honestly: answers are anonymous!

\section{Instructions of the second stage}


At the beginning of this stage, the 24 subjects (you included) will be randomly assigned to one of 6 groups of 4 individuals. Your group will not change during this experiment. You will never know the identity of the 3 other members of your group.

Each group will be composed of A Players and/or B Players. At the beginning of this game, the computer will give you your type. You will be the same type of player up to the end of this game. Your type was determined according to your answers in the previous stage. Next the instructions will explain to you the decisions you will have to make.

\section{Context}

You live in a community in which the government is planning a risk of pollution. In particular, the government experts have determined that pollution will be low with probability 0.5 , and high with probability 0.5 . To face this risk of pollution, you have the possibility to invest in order to reduce the level of pollution. You and the 3 other members of your group will receive an endowment of 10 tokens. You will have to allocate your entire endowment of 10 tokens between a private account and an environmental account.

The private account is an individual account for your own consumption. The environmental account is a collective account which will be used to improve environmental quality. When investing one token into the environmental account to improve environmental quality, your investment benefits you and all the members of your group. When investing one token into the private account, your investment benefits you alone. You will have to determine your level of investment into the environmental account between 0 and 10. The rest will be automatically invested into your private account.

Your total payoff, in relation to your investment in the environmental account, is indicated in the tables we have provided you with. However, your payoff will not be the same according to your type (A player or B). For each type of player, two tables are provided: one for low pollution, one for high pollution. The payoff is expressed in ECUs, with 40 ECUs $=1$ euro.

The computer will provide to you with a simulator for your payoff. You may simulate your investment into the environmental account. Then the simulator will indicate the 
payoff of an A player (in both states of pollution) and the one of a B player (in both states of pollution too).

Example 1: let us assume that you invest 3 tokens in the environmental account and that the 3 other members of your group invest a total of 10 tokens in this account. Moreover, let us assume that pollution at the end of this period is low.

- If you are an A player, your payoff at the end of the period is 670 ECUs.

- If you are a B player, your payoff at the end of the period is 622 ECUs.

Example 2: let us assume that you invest 7 tokens in the environmental account and that the 3 other members of your group invest a total of 15 tokens in this account. Moreover, let us assume that pollution at the end of this period is high.

- If you are an A player, your payoff at the end of the period is 350 ECUs.

- If you are a B player, your payoff at the end of the period is 120 ECUs.

You will have 3 minutes to make different simulations. Then, you will have to indicate your decision, between 0 and 10 tokens, to the computer. The level of pollution for each period will be randomly determined.

For your payoff, 2 periods will be randomly selected by one of the subjects. Your payoff will be equal to the average of your payoffs obtained during these two periods.

\section{Stage course}

Before the beginning of this stage, you will have to answers questions to test your understanding of this game.

The game will begin once everyone has answered the questions. You will play during 15 periods. At the end of each period, the computer will indicate a summary of useful information.

However, before you make your decision, a piece of information will appear on your screen. You are completely free to follow, or not, this piece of information. We remind you that all your decisions are anonymous. After the 15 periods, one subject will randomly determine the 2 periods that will detersmine your payoff. 


\section{GEB questionnaire}

1) I use energy-efficient bulbs.

2) If I am offered a plastic bag in a store, I take it.

3) I kill insects with a chemical insecticide.

4) I collect and recycle used paper.

5) When I do outdoor sports/activities, I stay within the allowed areas.

6) I wait until I have a full load before doing my laundry.

7) I use a cleaner made especially for bathrooms, rather than an all-purpose cleaner.

8) I wash dirty clothes without prewashing.

9) I reuse my shopping bags.

10) I use rechargeable batteries.

11) In the winter, I keep the heat on so that I do not have to wear a sweater.

12) I buy beverages in cans.

13) I bring empty bottles to a recycling bin.

14) In the winter, I leave the windows open for long periods of time to let in fresh air.

15) For longer journeys (more than 6h), I take an airplane.

16) The heater in my house is shut off late at night.

17) I buy products in refillable packages.

18) In winter, I turn down the heat when I leave my house for more than 4 hours.

19) In nearby areas, I use public transportation, ride a bike, or walk.

20) I buy clothing made from all-natural fabrics (e.g. silk, cotton, wool, or linen).

21) I prefer to shower rather than to take a bath.

22) I ride a bicycle, take public transportation, or walk to work or other.

23) I let water run until it is at the right temperature.

24) I put dead batteries in the garbage.

25) I turn the light off when I leave a room.

26) I leave the water on while brushing my teeth.

27) I turn off my computer when Im not using it.

28) I shower/bathe more than once a day. 


\section{LOT-R questionnaire}

1) In uncertain times, I usually expect the best.

2) It's easy for me to relax.

3) If something can go wrong for me, it will.

4) I'm always optimistic about my future.

5) I enjoy my friends a lot.

6) It's important for me to keep busy.

7) I hardly ever expect things to go my way.

8) I don't get upset too easily.

9) I rarely count on good things happening to me.

10) Overall, I expect more good things to happen to me than bad. 


\section{Earnings}

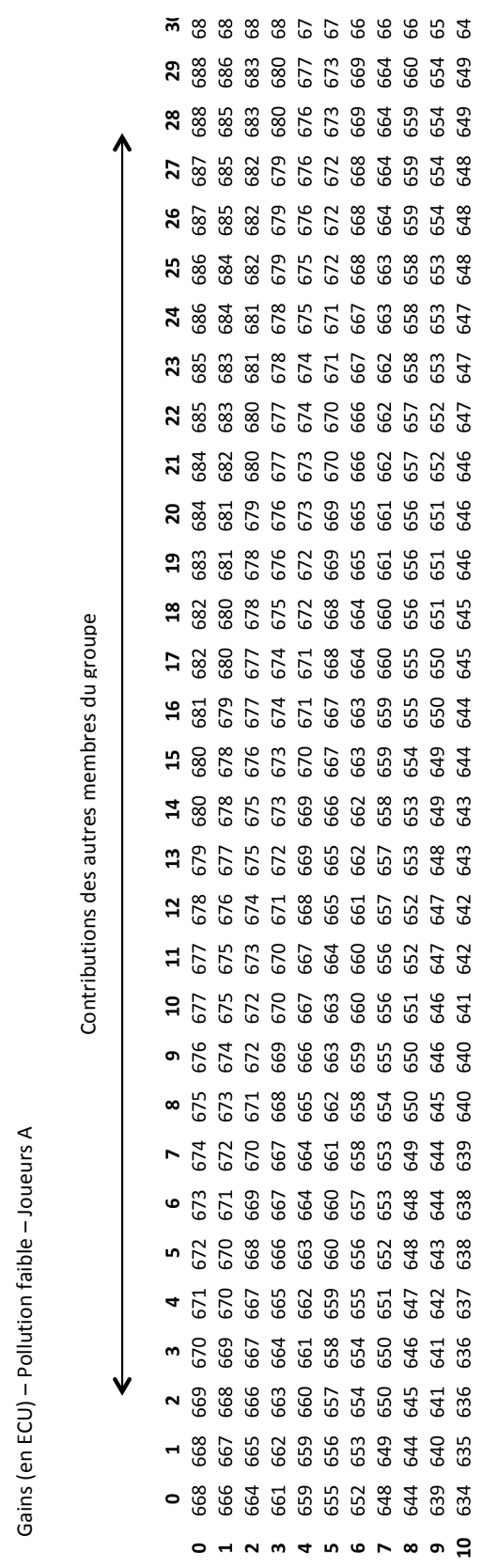

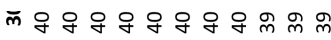

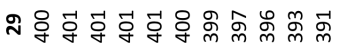

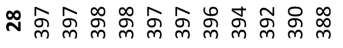

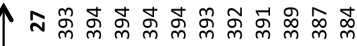

용 命 J్

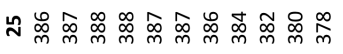

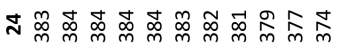

ఇ 命离

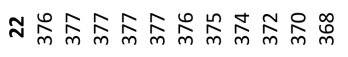

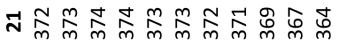

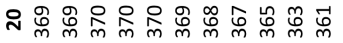

ᄀ

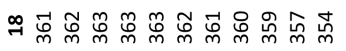

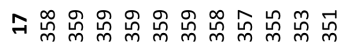

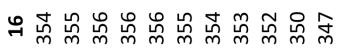

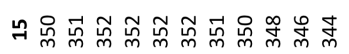

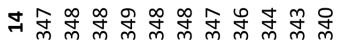

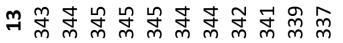

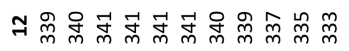

二

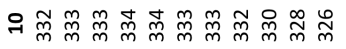

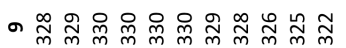

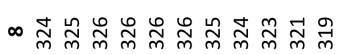

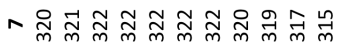

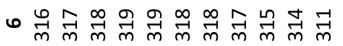

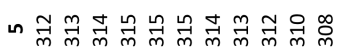

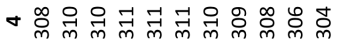

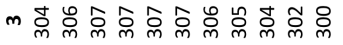

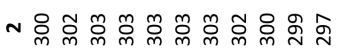

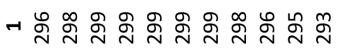

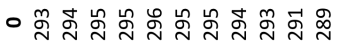

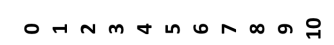




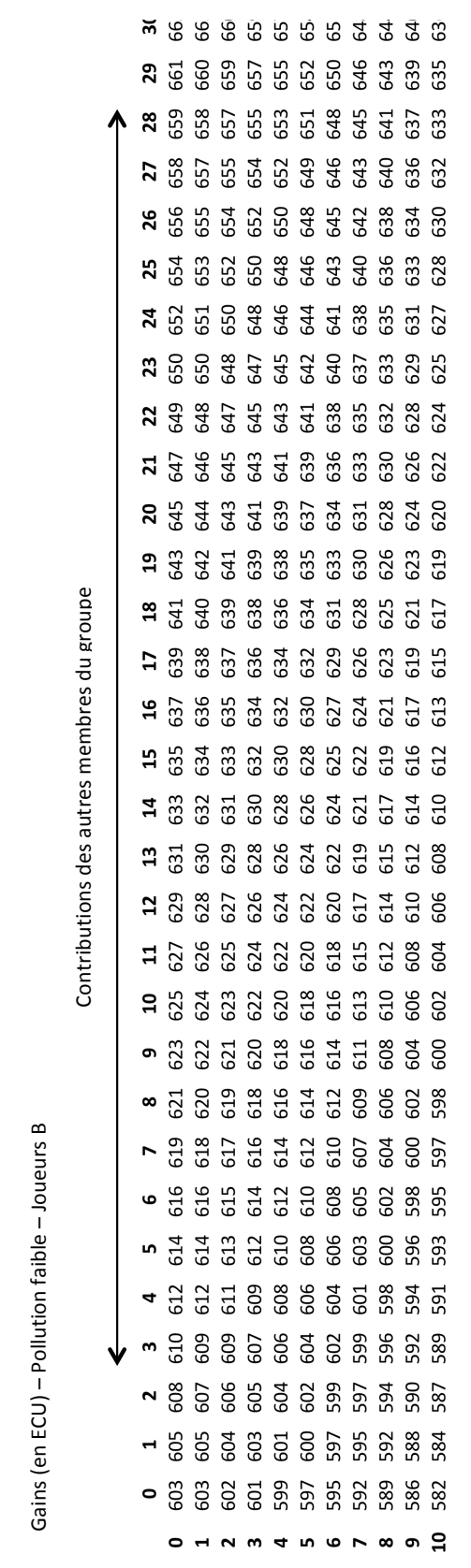

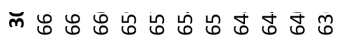

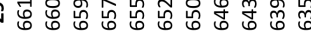

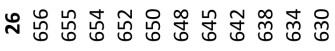

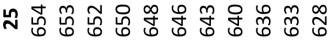

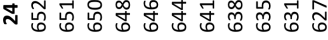

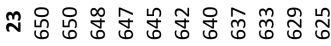

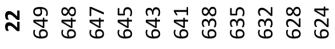

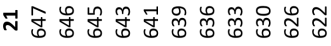

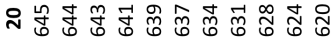

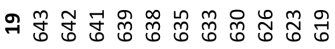

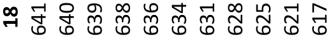

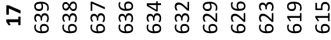

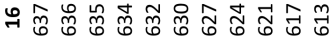

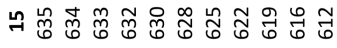

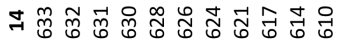

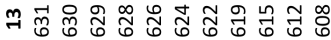

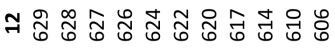

न

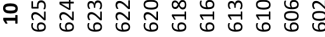

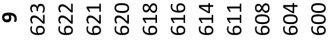

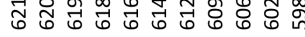

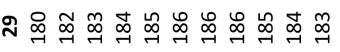

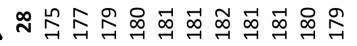

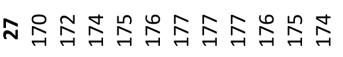

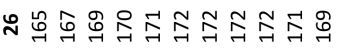

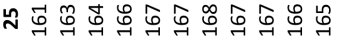

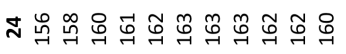

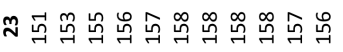

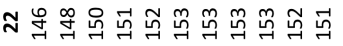

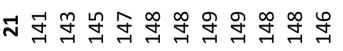

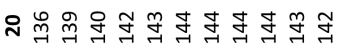

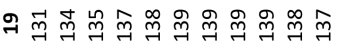

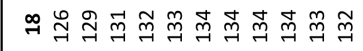

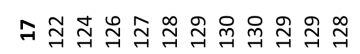

어

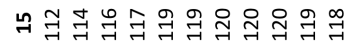

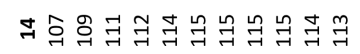

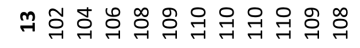

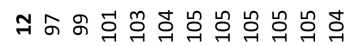

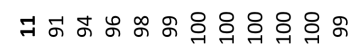

웅 ᄚ

の

め 옹

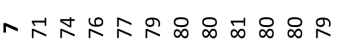

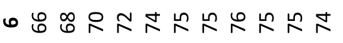

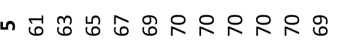

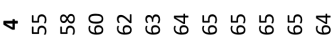

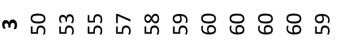

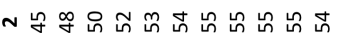

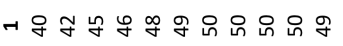

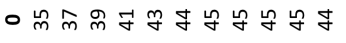

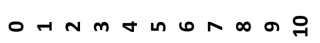




\section{References}

[1] Allcott, H., 2011. "Social Norms and Energy Conservation." Journal of Public Economics, 95: 1082-1095.

[2] Allcott, H. and T. Rogers, 2014. "The Short-Run and Long-Run Effects of Behavioral Interventions: Experimental Evidence from Energy Conservation." American Economic Review, 104: 3003-3037.

[3] Ayres, I., S. Raseman and A. Shih, 2013. "Evidence from two large field experiments that peer comparison feedback can reduce residential energy usage." Journal of Law, Economics and Organization, 29: 992-1022.

[4] Bénabou, R. and J. Tirole, 2003. "Intrinsic and Extrinsic Motivation." Review of Economic Studies, 70: 489-520.

[5] Bénabou, R. and J. Tirole, 2006. "Incentives and Prosocial Behavior." American Economic Review, 96: 1652-1678.

[6] Bernedo, M., P.J. Ferraro and M. Price, 2014. "The Persistent Impacts of NormBased Messaging and Their Implications for Water Conservation." Journal of Consumer Policy, 37: 437-452.

[7] Chaudhuri, A., 2011. "Sustaining cooperation in laboratory public goods experiments: a selective survey of the literature." Experimental Economics, 14: 47-83.

[8] Cochard F., M. Willinger et A. Xepapadeas, 2005. "Efficiency of Nonpoint Source Pollution Instruments: An Experimental Study" Environmental and Resource Economics, 30: 393-422.

[9] Corral-Verdugo, V., M. Bonnes, C. Tapia-Fonllem, B. Fraijo-Sing, M. Frias-Armenta et G. Carrus, 2009. "Correlates of pro-sustainability orientation: The affinity towards diversity." Journal of Environmental Psychology, 29: 34-43.

[10] Costa, D.L. and M.E. Kahn, 2013. "Energy conservation "nudges" and environmentalist ideology: evidence from a randomized electricity field experiment." Journal of the European Economic Association, 11: 680-702. 
[11] Crainich, D. et L. Eeckhoudt, 2008. "On the Intensity of Downside Risk Aversion." Journal of Risk and Uncertainty, 36: 267-276.

[12] Cropper, M.L. and W.E. Oates, 1992. "Environmental Economics: A Survey." Journal of Economic Literature, 30: 675-740.

[13] Croson, R. and M. Marks, 2001. "The effect of recommended contributions in the voluntary provision of public goods." Economic Inquiry, 39: 238-249.

[14] Dal Bó, E. and P. Dal Bó, 2014. " "Do the right thing:" The effects of moral suasion on cooperation." Journal of Public Economics, 117: 28-38.

[15] Dannenberg, A., A. Löschel, G. Paolacci, C. Reif et A. Tavoni, 2015. "On the Provision of Public Goods with Probabilistic and Ambiguous Thresholds." Environmental and Resource Economics, 61: 365-383.

[16] Davis, J., J.D. Green and A. Reed, 2009. "Interdependence with the environment: Commitment, interconnectedness, and environmental behavior." Journal of Environmental Psychology, 29: 173-180.

[17] Davis, J., B. Le and A.E. Coy, 2011. "Building a model of commitment to the natural environment to predict ecological behavior and willingness to sacrifice." Journal of Environmental Psychology, 31: 257-365.

[18] Delaney, J. and S. Jacobson, 2016. "Payments or Persuasion: Common Pool Resource Management with Price and Non-price Measures." Environmental and Resource Economics, 65: 747-772

[19] Dugar, S., 2010. "Nonmonetary sanctions and rewards in an experimental coordination game." Journal of Economic Behavior and Organization, 73: 377-386.

[20] Dugar, S., 2013. "Non-monetary incentives and opportunistic behavior: evidence from a laboratory public good game." Economic Inquiry, 51: 1374-1388.

[21] Egebark, J. and M. Ekström, 2016. "Can indifference make the world greener?" Journal of Environmental Economics and Management, 76: 1-13.

[22] Etner, J., M. Jeleva and P.A. Jouvet, 2007. "Risk Perceptions, Voluntary Contributions and Environmental Policy." Research in Economics, 61: 130-139. 
[23] Etner, J., M. Jeleva and P.A. Jouvet, 2009. "Pessimism or Optimism: a Justification to Voluntary Contributions Toward Environmental Quality." Australian Economic Papers, 48: 308-319.

[24] Falkinger, J., 1996. "Efficient private provision of public goods by rewarding deviations from average." Journal of Public Economics, 62: 413-422.

[25] Falkinger, J., E. Fehr, S. Gächter et R. Winter-Ebmer, 2000. "A Simple Mechanism for the Efficient Provision of Public Goods: Experimental Evidence." The American Economic Review, 90: 247-264.

[26] Farhi, E. and X. Gabaix, 2015. "Optimal Taxation with Behavioral Agents." Mimeo.

[27] Ferraro, P. and M.K. Price, 2013. "Using Non-Pecuniary Strategies to Influence Behavior: Evidence from a Large Scale Field Experiment." The Review of Economics and Statistics, 95: 64-73.

[28] Figuières, C., D. Masclet and M. Willinger, 2013. "Weak Moral Motivation Leads to the Decline of Voluntary Contributions." Journal of Public Economic Theory, 15: $745-772$.

[29] Fischbacher, U., S. Gächter et E. Fehr, 2001. "Are people conditionally cooperative? Evidence from a public goods experiment." Economics Letters, 71: 397-404.

[30] Frey, B.S., 1992. "Pricing and Regulating Affect Environmental Ethics" Environmental and Resource Economics, 2: 399-414.

[31] Glaesmer, H., W. Rief, A. Martin, R. Mewes, E. Brähler, M. Zenger et A. Hinz, 2012. "Psychometric properties and population based norms of the Life Orientation Test Revised (LOT-R)." British Journal of Health Psychology, 35: 472-482.

[32] Gneezy, U. and A. Rustichini, 2000. Pay enough or don't pay at all." The Quarterly Journal of Economics, 115: 791-810.

[33] Goldstein, N.J., R.B. Cialdini and V. Griskevicius, 2008. "A Room with a Viewpoint: Using Social Norms to Motivate Environmental Conservation in Hotels." Journal of Consumer Research, 35: 472-482. 
[34] Harding, M. and A. Hsiaw, 2014. "Goal Setting and Energy Conservation." Journal of Economic Behavior and Organization, 107: 209-227.

[35] Harrison, G.W. et J.A. List, 2004. "Field Experiments." Journal of Economic Literature, 42: 1009-1055.

[36] Hasson, R., A. Löfgren et M. Visser, 2010. "Climate change in a public goods game: Investment decision in mitigation versus adaptation." Ecological Economics, 70: 331338.

[37] Hasson, R., A. Löfgren et M. Visser, 2012. "Treatment effects of climate change risk on mitigation and adaptation behaviour in an experimental setting." South African Journal of Economic, 80: 415-430.

[38] Helfand, G.E, P. Berck and T. Maull, 2003. "The theory of pollution policy." Handbook of Environmental Economics, 1, ed. by K.-G. Mäler and J.R. Vincent, Elsevier Science.

[39] Kaiser, F.G., 1998. "A General Measure of Ecological Behavior." Journal of Applied Social Psychology, 28: 395-422.

[40] Kaiser, F.G. et A. Biel, 2000. ” Assessing general ecological behavior: A cross-cultural comparison between Switzerland and Sweden." European Journal of Psychological Assessment, 16: 44-52.

[41] Kaiser, F.G. et M. Wilson, 2000. "Assessing People's General Ecological Behavior: A Cross-Cultural Measure." Journal of Applied Social Psychology, 30: 952-978.

[42] Keser, C. et F. van Winden, 2000. "Conditional Cooperation and Voluntary Contributions to Public Goods." The Scandinavian Journal of Economics, 102: 23-39.

[43] Kimball, M., 1990. "Precautionary saving in the small and in the large." Econometrica, 58: 53-73.

[44] Ledyard, J., 1995. "Public Goods: A Survey of Experimental Research. In J. H. Kagel and A. E. Roth(eds.)." The Handbook of Experimental Economics, 111-194, Princeton, NJ: Princeton University Press. 
[45] Lefebvre, M. and A. Stenger, 2016. "Long-lasting effects of temporary incentives in public good games." BETA Working Paper 2016-25.

[46] Marks, M.B., D.E. Schansberg and R.T.A. Croson, 1999. "Using Suggested Contributions in Fundraising for Public Good. An Experimental Investigation of the Provision Point Mechanism." Nonprofit Management and Leadership, 9: 369-384.

[47] Masclet, D., C. Noussair, S. Tucker et M.C. Villeval, 2003. "Monetary and NonMonetary Punishment in the Voluntary Contribution Mechanism." The American Economic Review, 93: 366-380.

[48] Menezes, C., C. Geiss et T. Tressler, 1980. "Increasing downside risk." The American Economic Review, 70: 921-932.

[49] Milinski, M., R.D. Sommerfeld, H-J. Krambeck, F.A. Reed et J. Marotzke, 2008. "The collective-risk social dilemma and the prevention of simulated dangerous climate change." Proceedings of the National Academy of Sciences of the United States of America, 105: 2291-2294.

[50] Momsen, K. and T. Stoerk, 2014. "From intention to action: Can nudges help consumers to choose renewable energy?" Energy Policy, 74: 376-382.

[51] Nolan, J., W. Schultz, R.B. Cialdini, N. Goldstein and V. Griskevicius, 2008. "Normative Influence is Underdetected." Personality and Social Psychology Bulletin, 34: 913-923.

[52] Noussair, C.N., C.R. Plott et R.G. Riezman, 1995. "An experimental investigation of the patterns of international trade." The American Economic Review, 85: 462-491.

[53] Ouvrard, B. and S. Spaeter, 2016. "Environmental incentives: nudge or tax?" BETA Working Paper 2016-23.

[54] Oxoby, R.J. and J. Spraggon, 2007. In T.L. Cherry, S. Kroll and J.F. Shogren (Eds.), Experimental Methods, Environmental Economics, Routledge Publishing.

[55] Préget, R., P. Nguyen-Van et M. Willinger, 2016. "Who are the voluntary leaders? Experimental evidence from a sequential contribution game." Theory and Decision, 81: 581-599. 
[56] Rege, M. et K. Telle, 2004. "The impact of social approval and framing on cooperation in public good situations." Journal of Public Economics, 88: 1625-1644.

[57] Salanié F. and N. Treich, 2009. "Regulation in Happyville." The Economic Journal, 119: 665-679.

[58] Scannell, L. et R. Gifford, 2010. "Defining place attachment: A tripartite organizing framework." Journal of Environmental Psychology, 30: 1-10.

[59] Scheier, M.F. and C.S. Carver, 1985. "Optimism, Coping, and Health: Assessment and Implications of Generalized Outcome Expectancies." Health Psychology, 4: 219247.

[60] Scheier, M.F., C.S. Carver and M.W. Bridges, 1994. "Distinguishing Optimism From Neuroticism (and Trait Anxiety, Self-Mastery, and Self-Esteem): A Reevaluation of the Life Orientation Test." Journal of Personality and Social Psychology, 67: 10631078 .

[61] Schultz, W., J. Nolan, R.B. Cialdini, N. Goldstein and V. Griskevicius, 2007. "The Constructive, Destructive, and Reconstructive Power of Social Norms." Psychological Science, 18: 429-434.

[62] Spraggon J., 2002. "Exogeneous targeting instruments as a solution to group moral hazards" Journal of Public Economics, 84: 427-456.

[63] Sunstein, C.R., 2014. "Nudging: A Very Short Guide" Journal of Consumer Policy, 37: 583-588.

[64] Tavoni, A., A. Dannenberg, G. Kallis et A. Löschel, 2008. "Inequality, communication, and the avoidance of disastrous climate change in a public goods game." Proceedings of the National Academy of Sciences of the United States of America, 108: $11825-11829$.

[65] Thaler, Richard H. and Sustein Cass R., 2009. Nudge: Improving Decisions about Health, Wealth, and Happiness. Penguin Books.

[66] Tversky, A. et D. Kahneman, 1974. "Judgement under Uncertainty: Heuristics and Biases." Science, 185: 1124-1131. 
[67] Willinger, M., N. Ammar et A. Ennasri, 2014. "Performance of the ambient tax: does the nature of the damage matter?" Environmental and Resource Economics, 59: 479-502.

[68] Wooldridge, J.M., 2005. "Simple Solutions to the Initial Conditions Problem in Dynamic, Nonlinear Panel Data Models with Unobserved Heterogeneity." Journal of Applied Econometrics, 20: 39-54.

[69] Zenger, M., C. Finck, C. Zanon, W. Jimenez, S. Singer et A. Hinz, 2013. "Evaluation of the Latin American version of the Life Orientation Test-Revised." International Journal of Clinical and Health Psychology, 13: 243-252.

[70] Zizzo, D.J., 2010. "Experimenter demand effects in economic experiments." Experimental Economics, 13: 75-98. 